Portland State University

PDXScholar

Fall 12-11-2015

\title{
Check-In Frequency with Friends on Location-Based Social Networks: A Look at Homophily and Relational Closeness
}

Jacqueline $\mathrm{H}$. Vo

Portland State University

Follow this and additional works at: https://pdxscholar.library.pdx.edu/open_access_etds

Part of the Communication Technology and New Media Commons Let us know how access to this document benefits you.

Recommended Citation

Vo, Jacqueline H., "Check-In Frequency with Friends on Location-Based Social Networks: A Look at Homophily and Relational Closeness" (2015). Dissertations and Theses. Paper 2630.

https://doi.org/10.15760/etd.2626

This Thesis is brought to you for free and open access. It has been accepted for inclusion in Dissertations and Theses by an authorized administrator of PDXScholar. Please contact us if we can make this document more accessible: pdxscholar@pdx.edu. 
Check-In Frequency with Friends on Location-Based Social Networks:

A Look at Homophily and Relational Closeness

$$
\text { by }
$$

Jacqueline H. Vo

A thesis submitted in partial fulfillment of the requirements for the degree of

\author{
Master of Science \\ in \\ Communication
}

\author{
Thesis Committee: \\ Jeffrey Robinson, Chair \\ Lee Shaker \\ Cynthia-Lou Coleman
}

Portland State University

2015 
(C) 2015 Jacqueline H. Vo 


\begin{abstract}
This study examines factors associated with the frequency with which users of location-based social networks (LBSNs) "check-in" with their "friends." In addition to a variety of control factors (i.e., sex homophily, race homophily, geographic proximity, length of friendship, and "friendship" type, including non-romantic friend, romantic partner, and family), the central factors of interest were users' background and attitude homophily with, and relational closeness to, their "friends." Results demonstrate that relational closeness and "friendship" type (i.e., romantic partner) were significantly, positively associated with "check-in" frequency.
\end{abstract}




\section{ACKNOWLEGEMENTS}

I would never have been able to finish my thesis without the guidance of my committee members, help from my colleagues, and the unwavering support from my family and friends.

I would like to express my deepest gratitude to Dr. Robinson and Dr. Shaker for their guidance, support, and patience throughout my entire research process. The completion of this project wouldn't have been possible on my own without their constant motivation and continuous advice. A special thank you to Dr. Coleman, who was willing to participate on my final defense committee at the last moment and for her constructive feedback to improve my thesis.

I would also like to thank my friends and colleagues for their help with my data collection, and for their time and effort in reviewing and proofing my thesis.

Finally, I would like to heartily dedicate this thesis to my parents and my best friend who have been pillars of strength and support in all aspects of my life. My academic success is due to their constant encouragement and unconditional love. I could not have done this without them. 
PAGE

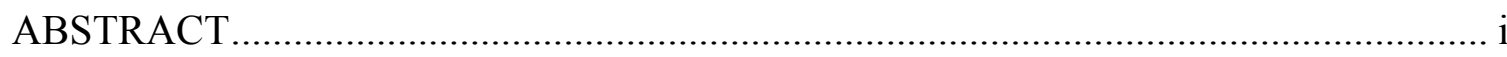

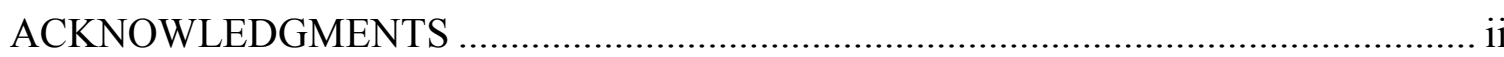

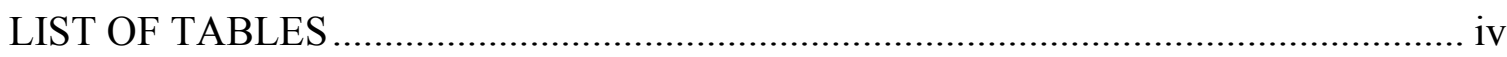

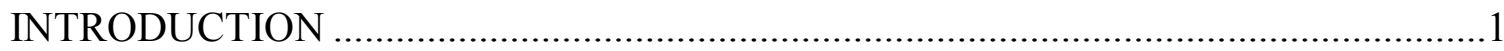

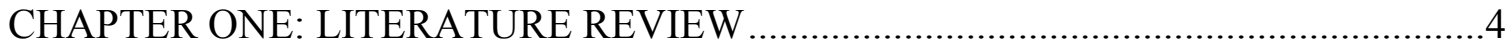

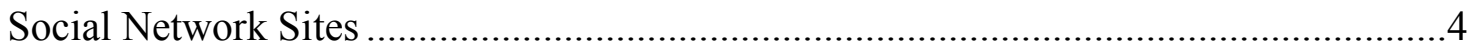

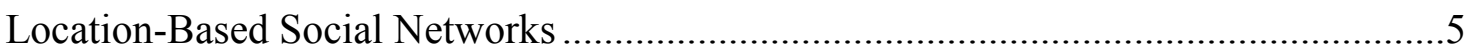

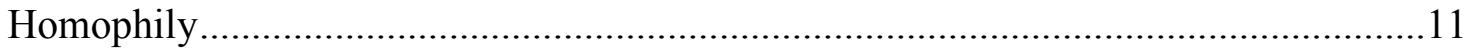

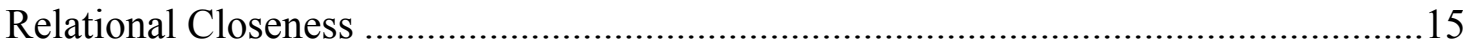

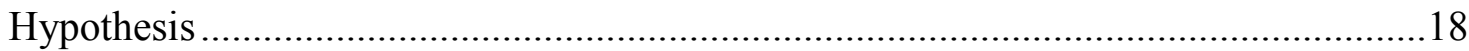

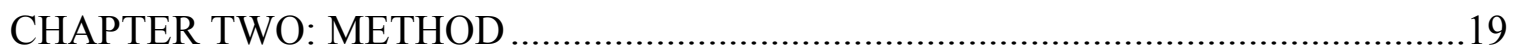

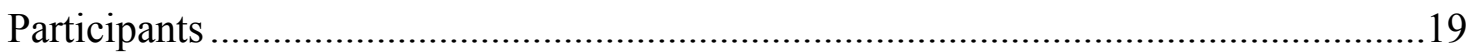

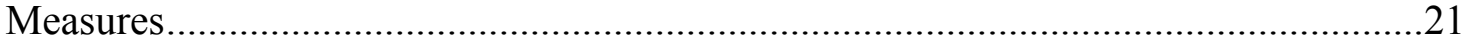

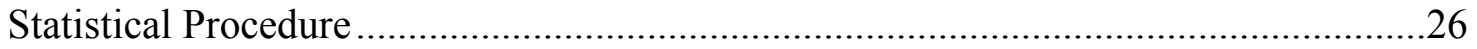

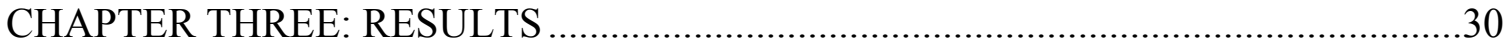

Users and Their "Friends" on Location-Based Social Networks ...................................30

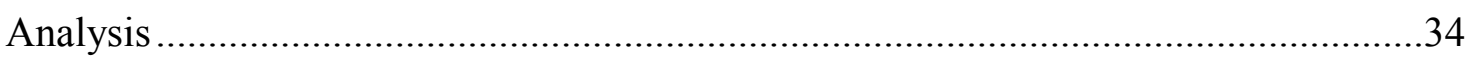

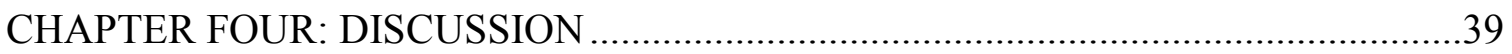

Strong Ties on Location-Based Social Networks ………..............................................

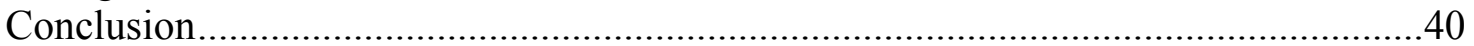

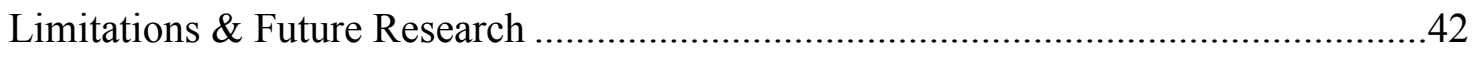

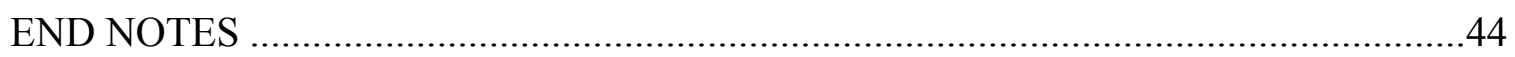

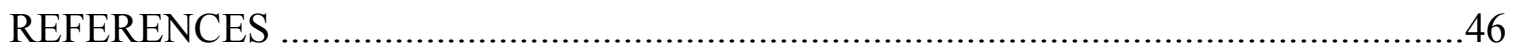

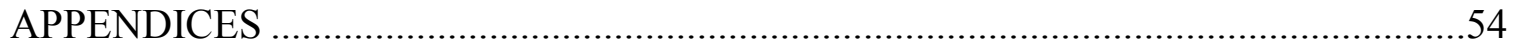

Appendix A: Consent Form and Data Collection Survey …………............................54

Appendix B: Multicollinearity Check ………………...........................................60 


\section{LIST OF TABLES}

TABLE

PAGE

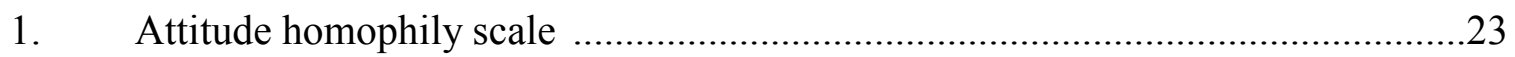

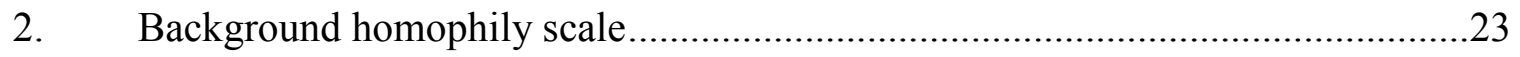

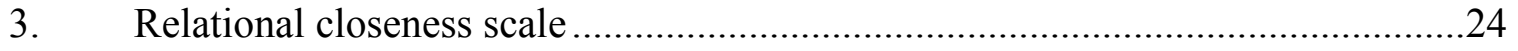

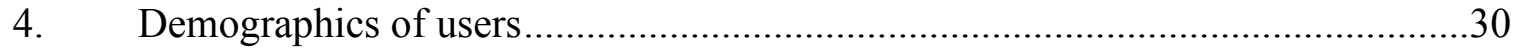

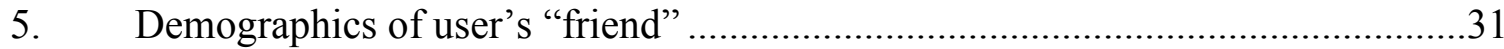

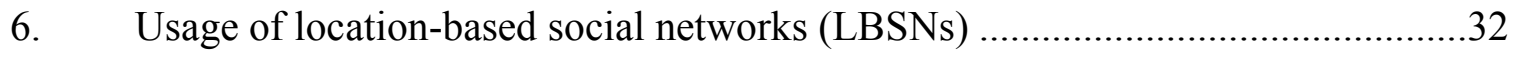

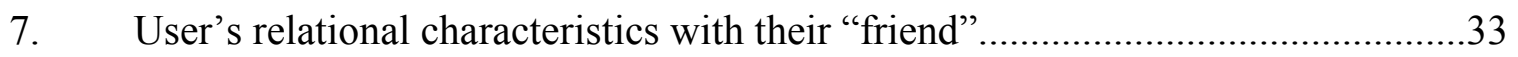

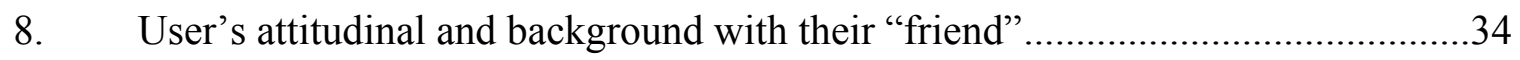

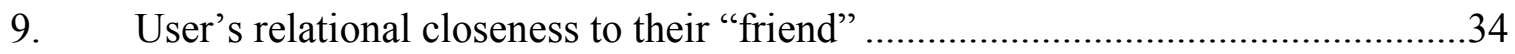

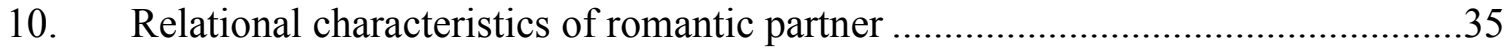

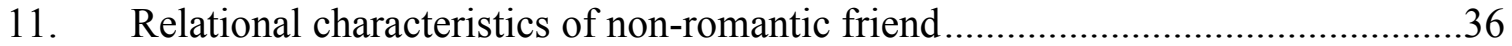

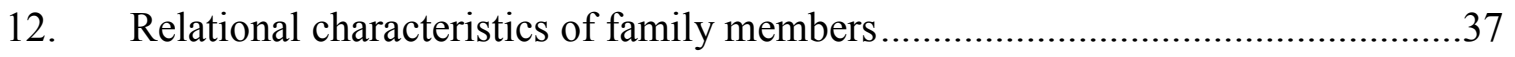

13. Logistic regression model predicting “check-in” frequency on LBSNs................38 


\section{INTRODUCTION}

As people are ever more mobile for work and leisure, they increasingly share information and connect with their "friends"i on various social network sites (e.g., Facebook) using their mobile devices. Social network sites (hereafter referred to as SNSs) have become one of the most popular, mobile-web vehicles by which users interact with other people who are socially relevant to them, such as their friends, family members, and co-workers. With the advent of smartphones (e.g., portable phones enabled with global-positioning systems and internet connectivity) and map services (e.g. Google Maps), location-based social networks (hereafter referred to as LBSNs), such as Foursquare ${ }^{\mathrm{ii}}$ and Facebook Places, ${ }^{\mathrm{iii}}$ have forged new frontiers for online interaction based on users' physical locations. Location-based social network users socialize with each other by sharing their current location in the form of "check-ins., "iv Sharing "checkins" allows users to announce and discuss real-world places they visit (e.g., while dining at local restaurants, shopping at local stores, visiting local establishments) as part of their social interaction online. This new phenomenon of "checking-in" has attracted more than 55 million registered users and surpassed 7 billion "check-ins," (Foursquare statistics, n.d.). In addition, more than 2 million businesses have claimed their "check-in" location to connect and interact with their customers (Foursquare statistics, n.d.).

Location-based social networks have become not only a new way for users to interact and share their experiences with their "friends" on the move, but it has also opened up a new avenue for users as consumers to interact with businesses and for businesses to interact with them. Research has found that the capacity to share where you currently are, what you are currently doing, and who you are currently with appeal to 
millions of users as a method for meeting up with friends, meeting new people, experiencing new things, and managing one's identity (Brimicombe \& Li, 2009; Cheng, Caverlee, Lee, \& Sui, 2011; Humphrey, 2010; Lindqvist, Cranshaw, Wiese, Hong, \& Zimmerman, 2011). In addition, previous research on LBSNs has also investigated users' "check-in" data in order to predict users' location and mobility patterns (e.g., Cheng et al., 2011; Lindqvist et al., 2011; Scellato et al., 2011; Scellato \& Mascolo, 2011). While past research has studied the uses and patterns of LBSNs, no one has ever examined the factors that predict the use of LBSNs in terms of "checking-in."

We know that from prior studies, there are two possible reasons why users may "check-in" with certain "friends" and not others. Studies on the formation, development, and maintenance of close social and personal relationships online and offline have emphasized the importance and prevalence of homophily, which is the tendency to interact with, and befriend, similar others (McPherson, Smith-Lovin, \& Cook, 2001). In addition, Ledbetter, Broeckelman-Post, and Krawsczyn (2011) found that as interaction on Facebook increased, perceived level of closeness also increased. In fact, researchers have claimed that frequent interactions tend to have stronger ties (Donath, 2007; Ledbetter et al., 2011). Given that these two factors tend to be associated with higher social interaction, this study predicts that "checking-in" on LBSN will also be positively associated with perceived homophily and relational closeness.

To address this hypothesis, the current thesis focuses on a specific type of social interaction on LBSN (i.e., "checking-in") and examines whether "checking-in" more frequently (vs. infrequently) with a "friend" is positively associated with perceived levels of homophily (attitude and background) and relational closeness. This focus allows a 
detailed statistical exploration of a basic, yet important, aspect of user interaction on LBSNs. There are two reasons why investigating the role of "checking-in" with "friends" is important. The findings of this study not only add to the growing marketing communication literature by providing insight on whom and why users as consumers interact on LBSN, but also offer implications for companies that wish to leverage LBSNs more effectively, whether the purpose is to deliver information and advertising, collect data on opinions and attitudes, or offer promotions and discounts. As more and more users become connected on-the-go, mobile-application designers may find the results of this study useful for designing better communication features to help facilitate a more fruitful interaction between users and their "friends" and in turn, a better return of investment for businesses on LBSNs.

This study begins by discussing SNSs and some of the communication features that aid social interactions online. After a brief introduction to SNSs, it then reviews some of the most popular location-based social networks and summarizes their popular uses. It then draws on scholarship on social and computer-mediated relationships to identify variables known to influence friendship formation and interaction online and offline. Chapter two lays out the hypothesis and the methodology to examine the hypothesis. Chapter three describes the data and provides details of the findings. Chapter four concludes with a discussion on the implications of the results. 


\section{CHAPTER ONE: LITERATURE REVIEW}

\section{Social Network Sites}

The term 'social network site' (SNS) refers to web-based services that give individuals three major capabilities: (1) the ability to construct a public or semi-public profile; (2) the ability to identify a list of other users with whom a connection is shared; and (3) the ability to view and track individual connections, as well as those made by others within the system (boyd \& Ellison, 2007, p. 211). To create an account on most SNSs, users are asked to provide basic information about themselves, including their birthday, hometown, relationship status, religious views, political views, interests, activities, education, work, and so on. Social-network sites have become a popular technological tool for users to connect, express themselves, and share their interests, lifestyle, and activities with their family, friends, acquaintances, co-workers, and even strangers (Bisgin, 2012; boyd \& Ellison, 2007). In fact, among internet-using, U.S. adults, 65\% reported using SNSs such as Facebook or LinkedIn (Madden \& Zickuhr, 2011), and 92\% of SNS-using adults have a Facebook profile (Hampton, Goulet, Ranie, \& Purcell, 2011). As the leading SNS, Facebook currently maintains a user base exceeding one billion active users worldwide (Facebook statistics, n.d.).

Facebook contains a wide variety of public and private communication features to facilitate relationship maintenance across a variety of ties. To interact and communicate with others, all users have a "status" where they write how they feel or what they are currently doing. Each user has a "wall" on their Facebook profile where their "friend" can leave them messages. These messages are then displayed on a "newsfeed," where other users can read, respond, or "like",vi the content. In fact, Hampton et al. (2011) found 
that the act of "liking" a friend's content is the most commonly performed daily activities on Facebook. Ellison et al. (2011) explains that the behavior of "liking" a friend's content serves as a relationship-maintenance strategy because it signals one's presence in a friend's network and shows support for the "friend." In addition to "liking" and commenting publicly, Facebook also allows users to communicate with their "friends" by sending private messages through chat or closed groups.

The choice to communicate publicly or privately is dependent on the type of relationship users have with a certain "friend.” Bryant and Marmo's (2009) Facebook analysis revealed that "friend" lists are comprised of five distinct types of relationships: close friends, casual friends, acquaintances, romantic partners, and outsiders (e.g., parents, bosses, and teachers). Participants in their study explained that most of their offline close friends are also their Facebook "friends"; However, that category accounted for only a small portion of their Facebook "friends." Participants referred to their casual friendships on Facebook as obligatory connections, and that most of their "friends" are neither close nor casual, but are acquaintances with whom they rarely interact on Facebook. The beauty of SNSs is that users can share personal information about themselves with different types of "friends" at the same time and keep in touch with "friends" from near and far. In fact, studies have found that users use SNSs to stay in touch with friends and relatives, especially those that they do not see often (Steinfield, Ellison, \& Lampe, 2008; Subrahmanyam, Reich, Waechter, \& Espinoza, 2008).

\section{Location-Based Social Networks}

When SNSs first emerged, they were only accessible through personal computers. However, recent technological advancements of "smart" mobile devices have allowed 
users to easily access their social-network accounts in both ways. While users have the option to access, communicate, and exchange information on SNSs via their personal computer, the options to access SNSs on smartphones has allowed them to easily and conveniently communicate with their "friends" at anytime, anywhere (Brimicombe \& Li, 2009). As mobile development continues to progress, users are willing to share more personal information. Information sharing is no longer just about what users are doing; Users are now sharing where they are and whom they are with (Brimicombe \& Li, 2009). The process of sharing one's current location has become known as “checkingin;" Users can share their location-related information by using a location-based social network (LBSN), such as Foursquare or Facebook Places to "check-in" to where they are at the moment (Brimicombe \& Li, 2009). The development of LBSNs was driven by an integration of technologies. By combining social networks and mobile phones with global positioning systems (GPS), LBSNs allow users "check-in" to places, build their status as a local of an establishment, and more easily locate the physical position of their "friends" (Brimicombe \& Li, 2009). "Checking-in" is seen as the central user activity in addition to viewing other users' locations and discussing with others the places they "checked-in." The widespread adoption of sharing one's location has attracted a great deal of attention in recent years. In fact, Foursquare has garnered 7 billion "check-ins" on its service (Foursquare statistics, n.d.).

Early LBSNs, such as Dodgeball, ${ }^{\text {vii }}$ relied on a mobile, short-message service (SMS). Dodgeball's service was dependent on manual "check-ins" via text messages from its users; Users "checked-in" by texting a location to its service and "check-ins" were read and stored as text messages (Humphrey, 2010). After Dodgeball was acquired 
by Google Inc. and was shut down in 2009, many other LBSNs, such as Foursquare and Facebook Places, emerged with more sophisticated, location-tracking techniques and newer features, offering users the ability to interact and keep up with their "friends" more easily. Now, users can search for "friends" and venues nearby via their smartphones. The sophisticated options to search and share location-tagged content appeal to millions of users as a convenient way to meet up with "friends," meet new people, and experience new things (Cheng et al., 2011; Humphrey, 2010; Lindqvist et al., 2011). While some of the functionalities of LBSNs are similar to SNSs (i.e., users can create a personalized profile, share content with their "friends," and search for information), LBSNs offer users novel ways to not only interact with their "friends," but also interact with local businesses. With hundreds of thousands of people "checking-in" every day, real-time information has led to the growing interest in LBSN marketing for many businesses. Businesses are building customer loyalty and increasing the chance of repeated visits and purchases by offering special discounts when users "check-in" to their place. Currently, there are hundreds of LBSNs, including the focal ones in the present study, outlined below.

Foursquare. Launched in 2009, Foursquare describes itself as a "mobile application that makes cities easier to use and more interesting to explore. It is a friendfinder, a social city guide and a game that challenges users to experience new things, and rewards them for doing so," (Lindqvist et al., 2011, p. 2). With a smartphone, Foursquare can track a user's current position or location and prompt them with a list of "friends" and venues nearby (Foursquare, n.d.). Using the recommendation list provided by Foursquare, users can "check-in" to a desired venue with their "friends." When a user 
performs a "check-in," there are several options to share their location: (1) make it visible to only their "friends" on Foursquare; (2) extend it to other SNSs, such as Facebook, allowing users to share where they are with a broader audience of "friends;" or (3) make it public so that anyone with Internet access can view it (Foursquare, n.d.). In addition to "checking-in," Foursquare tracks the history of "check-ins." The history includes all the places users have been and who they have been there with. Places on Foursquare are formed through the act of naming the place as determined by the user, as well as categorizing the place as determined by the general preset categories ${ }^{\text {viii }}$ in the application (Foursquare infographic, n.d.).

Foursquare is more than just a LBSN that allows users to "check-in" to places; It is a game that awards users for their "check-ins." Foursquare encourages users to experience new things (and places) and rewards them for their "check-ins" with both virtual and actual (i.e., objective) rewards (Cheng et al., 2011; Foursquare, n.d.; Lindqvist, 2011). Virtual rewards come in the forms of points to collect "badges" and "mayorships" based on the number of different "check-ins" performed by a user. Badges are awarded for reasons such as "checking-in" for the first time, or "checking-in" at the same place three times in one week. "Mayorships" are awarded to a single individual for having the most "check-ins" in a given place in the past 60 days, where only one "checkin" per day is counted. Some companies reward users by giving actual discounts for being the "mayor" of their business. For example, "mayors" of individual Starbucks stores can unlock their "mayor" offer and receive a \$1 discount on a frappucino (Grove, 2010b). In addition to "checking-in" to redeem incentives, Foursquare users can post photos of their visit and leave "tips" (i.e., advice or recommendations) for future visitors. 
Facebook Places. ${ }^{\text {ix }}$ As one of the world's most powerful SNSs, in 2010, Facebook launched a new feature to its service called Places (Facebook Places, n.d.). Even without tangible incentives and rewards, $90 \%$ of early adopters who have performed a "check-in" have done so using Facebook Places (Hargreaves, 2011). With multiple sharing options (i.e., content only viewable by "friends," viewable by "friendsof-friends," viewable by only certain "friends," or public to anyone on the Internet), Places encourage users to "discover new places and share favorites with 'friends,," (Facebook Places, n.d.). Places allow users to tag a location to their content, including current and past Facebook status updates, photos, and videos. Like Foursquare, the idea is to let their "friends" know where they have been, where they are headed to, and where they are now, in the form of a written post or photo (Facebook Places, n.d.). It is also to help users remember their favorite places and receive tips or recommendations from "friends" who have previously been at that location (Facebook Places, n.d.). Users who "check-in" can tag other "friends" who are with them, but only if their friends" privacy settings allow it. When a user tags a "friend" in their "check-in," it is as if that "friend" has also "checked-in" at that place them self.

There are many other emerging LBSNs including Google Latitude, ${ }^{\mathrm{x}}$ Path, ${ }^{\mathrm{xi}}$ and SCVNGR $^{\text {xii }}$ (see Li \& Chen, 2010 for an overview) and their features vary from service to service, but all LBSNs have one thing in common: As a key point of interaction, all LBSN users can exchange details of their current location with their "friends;" Users can share what they are doing, where they were, where they are going, and whom they are with at anytime, anywhere (Cheng et al., 2011; Cho, et al., 2011; Humphrey, 2010; Lindqvist et al., 2011). Location-based social networks have attracted millions of users 
for a variety of reasons. Some of the reasons why users subscribe to a LBSN service include: (1) to get access to relevant information (Users can keep up to date on what's happening and get useful information about a place provided from previous visitors, such as what kind of menu item to try or skip at a particular restaurant); (2) to arrange meetings more easily (Users can keep up with their "friends" and inform their "friends" where they are without contacting each other; It no longer requires multiple calls to find out who is available to hangout); (3) to discover new places (Users can discover new places from their friends" "check-ins" or discover nearby places suggested by the service that they would not have otherwise discovered own their own; (4) to earn rewards (Users can get tangible discounts at participating merchants for their "check-ins;" This type of rewards system has attracted many businesses to build customer loyalty and increase the chance of repeated visits and purchases; and (5) to maintain a virtual diary (Users can keep a personal location history that includes all of their previous "check-ins" along with any photos or recommendations they may have shared) (Lindqvist et al., 2011).

Beyond understanding why users "check-in," researchers have also studied where users "check-in" and with whom users "check-in.” In a study that observed over 22 million public "check-ins" on Foursquare, Cheng et al. (2011) found that users typically “check-in" to bars, restaurants, coffee shops, and places that reflect users' daily activities. Moreover, Cho et al. (2011) found that the type of connection or relationship a user has with his or her "friends" plays a significant role in the way users travel; Users are generally more likely to visit a distant place if the place is geographically close to an existing friend. 
As for whom users "check-in" with, Lindqvist et al. (2011) found that over half of the subjects in their study indicated that they are "friends" with users on Foursquare whom they do not personally know offline. Lindqvist et al. (2011) speculated that users connect with others whom they find interesting and can provide new places for them to check out. Whether LBSN users know or do not personally know the people on their "friends" list, these "friendship" connections are not arbitrary. Past research on friendship formation suggests that, while we might want to believe that our decisions about who we want to interact with are highly variable, they actually exhibit underlying, organized patterns. The following section explains why we tend to befriend others with similar characteristics.

\section{Homophily}

Friendship scholars have long recognized that most people tend to befriend others who are similar to them, a tendency known as homophily (McPherson et al., 2001). Lazardfeld and Merton (1954) defined homophily as "a tendency for friendships to form between those who are alike in some designated respect" (p. 23). They explained that two individuals are more likely to have a connection or friendship if they are similar to each other. However, the converse is also true: If two people are connected, then they are more likely to have common characteristics or attributes (McPherson \& Smith-Lovin, 1987). Monge and Contractor (2003) suggested that people characterize themselves in two ways: (1) by ascribed characteristics, such as race/ethnicity, gender, and age (Turner, 1987); and (2) by similarity based on values, attitudes, and beliefs (Byrne, 1971).

The degree of similarity between two individuals has been used to explain realworld relationships, ranging from friendship (Shrum, Cheek, \& Hunter, 1988; Verbrugge, 
1983) to marriage (Kalmijn, 1998) to casual acquaintances (Hampton \& Wellman, 2001). Particularly, early homophily studies focused on ascribed characteristics such as race/ethnicity, gender, and age to examine how friendships are formed in group settings, such as school children and college students (McPherson et al., 2001). Some evidence is provided below.

In a study on friendship in school, Shrum et al. (1988) found that African American youth and adults tend to befriend others racially or ethnically similar to themselves. Similarly, Doyle and Kao's (2004) study on friendship choice found that adolescent students prefer racially homophilous friendships; Results revealed that $92.4 \%$ of white adolescent students listed a white best friend and $86.7 \%$ of black adolescent students listed a black best friend when asked to list the race of their best friend. Other studies have similarly found strong evidence of segregation in racial friendships (e.g., Moody, 2001; Mouw \& Entwisle, 2006).

In Verbrugge's (1977) study on adult friendships, $90 \%$ of men and $68 \%$ of women mentioned a same-sex person as their closest friend. He added that the less similar two people are in social characteristics (e.g., occupation, employment status, educational attainment, religious preference, political preference, nationality, age, marital status, sex, and length of residency), the less likely they are to be close friends (Verbrugge, 1977). Abel and Sahinkaya (1962) showed that same-sex preference is exhibited at a young age. In their preschool sample, children were presented with 16 photographs of eight girls and eight boys and were asked to pick one who they would choose as a friend; Results showed that both girls and boys tend to choose members of the same sex. 
McPherson et al.'s (2001) study suggested that age homophily in friendship is strongly based on a person's life stage. They explained that friendships are formed at different stages, such as during school, in college, and at work. For instance, friendships that are formed in classrooms are likely to be similar in age because the education system places students in certain classes based on their age, thus, friendships in classrooms induced strong homophily (McPherson et al., 2001).

Research on offline friendships has also shown that the closer the physical distance between two individuals, the more likely the friendship will be a success (Hays, 1985; Mesch \& Talmud, 2007; Priest \& Sawyer, 1967). Rogers and Shoemaker (1971) explained that common location provides common social context and opportunities and motivations for interaction. The closer two individuals are geographically, the more opportunities they have to participate in joint activities (Oswald \& Clark, 2003). For example, in Festinger, Schachter, and Back's (1950) study, they asked residents of a housing complex to name three people in the complex with whom they socialized with the most and found that friendships are more likely to form when people are proximate (i.e., The person who lived next door was listed most frequently, followed by the person who lived two doors down, and so on).

Two other major factors that are predictive of friendship formation are similarity of attitudes and backgrounds (McCroskey, McCroskey, \& Richmond, 2006). In a study on the acquaintance process in a college dormitory, Newcomb (1961) found that development of friendship was highly dependent on common attitudes. Roommates selected as being similar were much more likely to end up being friends. Likewise, 
Aboud and Mendelson (1996) found that individuals were more likely to participate in joint activities with others who share similar attitudes and beliefs.

The central argument of this section has been that friendships are more likely to occur when two individuals are similar to each other in a number of stable ways. The findings of these studies suggest that there are two ways that homophilous ties are formed: (1) by demographic make-up and/or nature of a group, meaning that, if a group is made up of similar people, then only similarities can form and, thus, homophily is the result; and (2) by choice, meaning that, even if individuals have the option to befriend people that are different than themselves, people will likely choose to be friends with people that are similar to themselves, and thus homophily is the cause (McPherson \& Smith-Lovin, 1987). Homophily based on choice suggests that, even though people have the ability to form dissimilar ties, only homophilous ties are formed. A study conducted by Lauw, Shafer, Agrawal and Ntoulas (2010) showed this distinction. Lauw et al. studied users of LiveJournal, a blogging and social networking site, and found that having similar interests make friendships significantly more likely, but being friends before joining LiveJournal also makes a pair of users more likely to share common interests. LiveJournal users' “friending” behavior echoed McPherson and Smith-Lovin's (1987) theoretical explanation of induced and choice homophily: Either friendships were formed through searching for others with similar interests, or friendships were already established before joining the site.

Induced and choice homophily are also evident on other SNSs such as Facebook. Facebook provides users the ability to share and search for others with similar interests, likes and dislikes, and perspectives beyond their geographic location (Facebook Places, 
n.d.). On SNSs, physical locality becomes less important because factors such as common interests displayed on users' profiles make it easier for individuals to find others that are similar or dissimilar to themselves (Papacharissi, 2002a; Papacharissi, 2002b; \& Wellman et al., 1996). However, even with the ability for people to search for others (dis)similar to them, Lewis, Gonzalez and Kaufman (2012) found that people tend to selfsegregate themselves on the basis of gender, race, and socioeconomic status on Facebook.

Homophily in social relationships is frequent because it provides important rewards. Similar individuals are likely to participate in joint activities with others who have similar interests and to receive validation of their attitudes and beliefs (Aboud \& Mendelson, 1996). Because participation in the same activities increases the frequency of social interaction and provides social support and validation, it is not surprising that similarity has been associated with stable and strong ties (Hallinan and Kubitschek, 1988). Related to, but conceptually distinct from, tie strength is a construct of homophily (Brown \& Reingen, 1987). The more similar two individuals are, the stronger the social tie connecting two (Granovetter, 1973; McPherson \& Smith-Lovin, 1987).

\section{Relational Closeness}

Tie strength has been an important concept and a measure in the analysis of both online and offline relationships (Wasserman \& Faust, 1995). Tie strength is often measured by assessing the level of relational closeness between individuals, with the assumption that the closer two people are, the stronger the tie (Dibble, Livine, \& Park, 2012; Marsden \& Campbell, 1984). In Granovetter's (1973) landmark work looking at tie strength, he defined it as "a combination of the amount of time, the emotional intensity, 
the intimacy (mutual confiding), and the reciprocal services which characterize the tie," (pp. 1361). Similarly, Kelly et al. (1983) referred to closeness as strong, frequent, varied, and enduring relationships, and cite frequency of interconnectedness as one of the indicators of a close relationship.

Researchers point out that the primary idea behind tie strength is that, amongst our network of friends (online or offline), we have friends with whom we are close to (strong ties) and friends with whom we are less close to (weak ties) (Granovetter, 1973; Kelley et al., 1983; Marsden \& Campbell, 1984). More specifically, strong social ties typically exist between close connections, such as friends, romantic partners, and family members; Such relationships exhibit behavior that reflects emotionality, interdependence, and intimacy (i.e., a high level of closeness). By contrast, weak ties are casual contacts that are more loosely connected to an individual's social network (e.g., acquaintances and coworkers); Such relationships do not require a lot of invested time and intimacy.

Weak ties have been found to provide access to useful information and new people, and to generate creative ideas (Burke et al., 2011; Granovetter, 1973). However, Brown and Reingen (1987) argued that strong ties are more important than weak ties in facilitating information flow between individuals. They found that, when people are in search of information, strong ties are more likely to be activated as sources of information than weak ties and, in addition, strong ties are perceived as more influential than weak ties (Brown \& Reingen, 1987). They speculated that this is because of the greater frequency of communication between individuals connected by strong ties.

Studies on social network and tie formation suggest that users join SNSs to maintain existing relationships, often with strong ties from offline connections as 
opposed to meeting new people (Lampe et al., 2007). When looking at dyadic interaction patterns on Facebook, Ledbetter and colleagues (2011) found that frequency of communication (e.g., wall posts, private messages, comments) was positively associated with perceived relational closeness. The time and effort to perform activities - such as commenting on, or "liking," a friend's status update - signals an investment in the relationship. This type of act of friendship maintenance is often referred to as social grooming, which is the communication or activities exchanged between users to maintain friendships (Donath, 2007).

While users have opportunities to create content visible only to a subset of their network, many users share information with their entire network of "friends" with whom they have widely varying feelings of closeness (Gilbert \& Karahalios, 2009). Such public sharing defies traditional models of self-disclosure, which presume that disclosures are generally restricted to close, trusted associates (Derlega \& Chaikin, 1977). However, recent empirical data suggests that SNS users have more close connections (Hampton et al., 2011), face-to-face interactions with close friends (Brandtzaeg, 2012), and more acquaintances (Hampton et al., 2011) than non-users.

Moreover, strongly-tied pairs tend to use more media to communicate with each other than do weakly-tied pairs, a phenomenon Haythornthwaite (2005) called media multiplexity. She explained that weak ties rely on passive interaction opportunities whereas strong ties use multiple means of communication to develop strong relations. In addition, Haythornthwaite (2007) claimed that ties are strong when individuals engage in many relations, self-disclosure, or support, whereas weak ties do not include frequent contact with other online individuals. Given the foregoing definitions, this study 
conceptualizes relational closeness as a subjective experience of intimacy, emotional intensity, and frequency of interconnectedness between two individuals (Dibble et al., 2012; Granovetter, 1973; Kelley et al., 1983).

\section{Hypothesis}

The chief goal of this study was to examine factors associated with "check-in" frequency in the context of location-based social networks (LBSNs). More specifically, is "checking-in" more frequently (vs. infrequently) with a "friend" positively associated with perceived homophily and relational closeness? Based on the aforementioned review of literature on homophily and relational closeness, this study hypothesizes that:

H1: Users" "check-in" frequency with their "friend" on LBSN will be positively associated with perceived homophily and relational closeness. 


\section{CHAPTER TWO: METHOD}

\section{Participants}

This study hypothesized that users" "check-in" frequency with their "friend" on LBSN will be positively associated with perceived homophily and relational closeness. Participants of interest included individuals who have used and or were currently using a LBSN to "check-in" to places with their "friends." In order to recruit users of LBSNs, this study utilized Amazon.com's Mechanical Turk (MTurk). MTurk is a crowdsourcing, internet marketplace that enables social scientists to recruit individuals to fill out surveys for a price. These individuals are registered survey takers or what MTurk terms as "workers" on their site. This purposive ${ }^{\text {xiii }}$ recruitment method was chosen as a way to obtain a diverse pool of LBSN users in MTurk's large database of registered survey takers nationally.

This study utilized filtering options provided on MTurk to recruit participants. Only LBSN users who were at least 18 years old, from the Unites States, and had acceptably completed above $90 \%$ of at least 50 previous surveys on MTurk were eligible to participate in the survey. It was imperative to gather data for users ages 18 or older in the U.S. because the greatest number of U.S. adults who use a LBSN is between the ages of 18-29 (Zickuhr \& Smith, 2010). The survey completion filter was used to ensure that participants were thoughtful survey takers who have completed surveys from start to finish. The survey was created on Qualtrics and participants were presented with an informed consent before taking the survey (see Appendix A). Participants consented by clicking a "proceed" button and declined by clicking a "decline" button. Participants were allowed a maximum of 50 minutes to complete the survey, which normally took an 
average of 2 minutes and 45 seconds to complete. Qualified participants were paid $\$ 0.25$ for completing the 140-item survey.

Although compensation rate and survey length may affect participation on MTurk, evidence suggests that MTurk generates data that is at least reliable as data obtained via traditional survey methods (Buhrmester, Kwang, \& Gosling, 2011). In addition, this study was reviewed and approved by Portland State University's Institutional Review Board (IRB) and the survey was available to complete on MTurk from September 24 to October 15 of 2012. The complete survey can be found in Appendix A.

In order to reach the targeted community of LBSN users on MTurk, a screening question was used to ask whether participants have used a LBSN to "check-in" to places. Participants who answered "yes" were able to proceed further and complete the survey, and participants who indicated "no" were thanked for their time and effort. In addition, to ensure that participants completed the survey attentively, two filtering statements were randomly placed in the survey including: "In this row, select Strongly Agree" and "In this row, select Somewhat Agree." Participants who selected the correct statements were considered attentive in answering the questions in the survey, and those that did not select the correct statements were considered not attentive and thus, were removed from analysis.

Of the 764 participants who attempted to take the survey, only 449 were qualified. In order to qualify, participants had to have used or were currently using a LBSN to check-in to places. Of the 764 participants who attempted to take the survey, 315 indicated that they do not use a LBSN to check-in to places and thus, were not permitted 
to proceed further in the survey. Of the 449 participants, 415 completed the survey from start to finish. Of the 415 surveys, thirty-four of these surveys were omitted because participants did not accurately select the filtering statements, and thus did not demonstrate adequate attention to the survey. A final 63 surveys were omitted because participants provided consistently polar answers (e.g., all '1's or all '7's on a 7-point Likert-type scale) to questions that were designed to generate opposite answers (e.g., one forward- and one reverse-coded question); This was another indication of participants' lack of attention or seriousness in taking the survey. In sum, 352 surveys were retained for analysis.

\section{Measures}

Participants filled out a 140 -item survey reporting on the following measures: demographic characteristics, usage of LBSNs, homophilous characteristics, and relational characteristics. In order to evaluate whether users' "check-in" frequency with their "friend" on LBSN will be positively associated with perceived homophily and relational closeness, it was important to obtain a range of frequent and infrequent "check-in" data. Thus, participants were encouraged to log into their LBSN account to verify the last, most recent "friend" they "checked-in" with versus asking participants whom they "checked-in" with most often. This procedure of identifying the last, most recent "friend" not only promoted a range of frequent and infrequent "check-in" data, but also a range of relationships of these "friends." Participants were then asked to provide a first name (only) or initials of their "friend" in order to encourage participants to focus on that person. 
Demographics of user. Participants were asked to provide their age, sex, race/ethnicity, and educational level completed (See Table 4).

Demographics of user's "friend." Participants were asked to estimate their "friend's" sex, age, and race/ethnicity (See Table 5).

Usage of LBSNs. Participants were asked to report their usage of LBSNs by indicating the type of LBSN they frequently use to "check-in" to places, how many "friends" they have on their [LBSN], and specifically their "check-in" frequency with their most recent "friend." In addition, participants were asked to report on the types of places or venues at which they typically "checked-in" with this particular "friend." Participants were allowed to report on multiple "check-in" venues (See Table 6).

“Check-in" frequency with "friends." In order to assess the dependent variable, "check-in" frequency, participants were asked "How often do you check-in to places with [name of friend]?" This measure was recoded into two categories "more frequently" (i.e., users who "check-in" either "Once a week," "2-3 Times a Week," "More than 3 times a week") and "less frequently" (i.e., users who "checked-in" either "2-3 Times a Month," "Once a Month," or "Less than Once a Month"), where 1 = "checking-in" more frequently and $0=$ "checking-in" less frequently (See Table 6).

Homophilous characteristics. In order to evaluate similarities between users and their "friend," participants were asked to evaluate on the following homophilous characteristics: attitudinal homophily (McCroskey et al., 2006), background homophily (McCroskey et al., 2006), sex homophily, and race homophily.

Attitudinal homophily. Participants were asked to evaluate their attitudinal homophily with their "friend" using McCroskey et al.'s (2006) attitude homophily scale. 
This 7-point Likert type scale $(1=$ Strongly Disagree; $2=$ Disagree; $3=$ Somewhat

Disagree; 4 = Neither; $5=$ Somewhat Agree; $6=$ Agree; $7=$ Strongly Agree) consisted of 15 items (See Table 1). Participants' scores were averaged across the fifteen questions to obtain a single, continuous variable with values ranging from 1 to 7 .

Table 1.

Attitude Homophily Scale Attitude Homophily

(1) This person thinks like me.

(2) This person doesn't behave like me. (reverse coded)

(3) This person is different from me. (reverse coded)

(4) This person shares my values.

(5) This person is like me.

(6) This person treats people like I do.

(7) This person doesn't think like me. (reverse coded)

(8) This person is similar to me.

(9) This person doesn't share my values. (reverse coded)

(10) This person behaves like me.

(11) This person is unlike me. (reverse coded).

(12) This person doesn't treat people like I do. (reverse coded)

(13) This person has thoughts and ideas that are similar to mine.

(14) This person expresses attitudes different from mine. (reverse coded)

(15) This person has a lot in common with me.

Background homophily. Participants were asked to evaluate their background homophily with their "friend" using McCroskey et al.'s (2006) background homophily scale. This 7-point Likert type scale $(1=$ Strongly Disagree; $2=$ Disagree; $3=$ Somewhat Disagree; $4=$ Neither; $5=$ Somewhat Agree; $6=$ Agree; $7=$ Strongly Agree) consisted of 10 items (See Table 2 below). The scores were averaged across the ten questions to obtain a single continuous variable with values ranging from 1 to 7.

Table 2.

Background Homophily Scale

Background Homophily

(1) This person is from a social class similar to mine.

(2) This person's status is different from mine. (reverse coded)

(3) This person is from an economic situation different from mine. (reverse coded)

(4) This person's background is similar to mine.

(5) This person's status is like mine. 
(6) This person is from a social class different from mine. (reverse coded)

Table 2. Cont.

Background Homophily

(7) This person is from an economic situation like mine.

(8) This person's background is different from mine. (reverse coded)

(9) This person and I come from a similar geographic region.

(10) This person's life as a child was similar to mine.

Sex and race homophily. Sex and race homophily were derived from extant measures. Participants were coded as being sex homophilous with their "friend" if their sexes matched, and non-homophilous if their sexes differed, where $1=$ homophilous, $0=$ not homophilous. In addition, participants were coded as being racially homophilous with their "friend" if their races matched, and non-homophilous if their races differed, where 1 $=$ homophilous, $0=$ not homophilous .

Relational closeness characteristics. In order to analyze the level of relational closeness between users and their "friend," participants were asked to evaluate on the follow characteristics: level of relational closeness (Dibble et al., 2011), type of relationship, length of friendship, and geographic proximity.

Relational closeness. Participants were asked to evaluate their level of relational closeness with their "friend" using Dibble et al.'s (2011) Unidimensional Relationship Closeness Scale (URCS). This 7-point Likert-type scale $(1=$ Strongly Disagree; $2=$ Disagree; 3 = Somewhat Disagree; $4=$ Neither; $5=$ Somewhat Agree; $6=$ Agree; $7=$ Strongly Agree) consisted of 12 items (See Table 3 below). The scores were averaged across twelve items to obtain a continuous variable that ranged from 1 to 7 .

Table 3.

Relational Closeness Scale Relational Closeness

(1) My relationship with [name of friend] is close.

(2) When we are apart, I miss [name of friend] a great deal.

(3) [Name of friend] and I disclose important personal things to each other. 
(4) [Name of friend] and I have a strong connection.

Table 3. Cont.

Relational Closeness

(5) [Name of friend] and I want to spend time together.

(6) I'm sure of my relationship with [name of friend].

(7) [Name of friend] is a priority in my life.

(8) My [name of friend] and I do a lot of things together.

(9) When I have free time I choose to spend it alone with [name of friend].

(10) I think about my [name of friend] a lot.

(11) My relationship with my [name of friend] is important in my life.

(12) I consider my [name of friend] when making important decisions.

User's relationship with their "friend." Participants were also asked to indicate the type of person or relationship this "friend" constituted. The type of person or relationship was determined by having participants indicate whether this most recent "friend" is a: (1) family member; (2) a non-romantic friend; (3) a romantic friend; or (4) a spouse/legal partner. Since a romantic friend could also likely be a spouse/legal partner, it was recoded into one variable, "romantic partner." In total, there were three relationship dummy variables that were used for analysis: (1) "family member" ( $1=$ family, $0=$ false $)$; (2) "non-romantic friend" $(1=$ friend, $0=$ false $)$; and $(3)$ "romantic partner" $(1=$ romantic partner, $0=$ false) (See Table 7).

Length of friendship. Participants were asked to indicate how long they have known their "friend" by estimating the number of years they have known each other. This measure was dichotomized into "less than 5 years" (i.e., "Less than 5 years") and "more than 5 years" (i.e., "6-10 years"; "11-20 years"; "21-30 years”; “31-40 years"; “41-50 years"; and "More than 50 years"), where $1=$ known for more than 5 years, and $0=$ known for less than 5 years (See Table 7).

Geographic proximity. Participants were asked to indicate the geographic distance in which they lived away from their "friend." Geographic proximity was 
calculated in terms of miles of separation between subjects and their "friend." This measure was dichotomized into "less than 10 miles away" (i.e., "Less than 10 miles away") and "more than 10 miles away" (i.e., "11-20 miles"; "21-30 miles"; "31-40 miles"; "41-50" miles; and "More than 50 miles."), where $1=$ lives more than 10 miles away, and $0=$ lives less than 10 miles away (See Table 7).

\section{Statistical procedure}

To investigate my hypothesis, logistic regression was used to analyze the relationship between the independent variables (attitude homophily, background homophily, sex homophily, race homophily, relational closeness, geographic proximity, length of friendship, and "friendship" types including non-romantic friend, romantic partner, and family) and dependent variable ("check-in” frequency). Logistic regression was conducted following the procedures described by Menard (2002). This method was selected because logistic regression allows observations of a binary dependent variable and one or more independent variables that can be either continuous or categorical. In this case, the dependent variable, "check-in" frequency, is a categorical binary variable (1 $=$ "checking-in" more frequently and $0=$ "checking-in" less frequently) with three continuous independent variables (attitude homophily, background homophily, and relational closeness) and seven categorical independent variables (sex homophily, race homophily, geographic proximity, length of friendship, and "friendship" types including non-romantic friend, romantic partner, and family). All of the categorical independent variables were based on dummy coding, which allowed for a dichotomous outcome: sex homophily, $1=$ homophilous, $0=$ not homophilous; race homophily, $1=$ homophilous, 0 $=$ not homophilous, geographic proximity, $1=$ lives more than 10 miles away, $0=$ lives 
less than 10 miles away, length of friendship, $1=$ known for more than 5 years, $0=$ known for less than 5 years, and friendship types, family member, $1=$ family, $0=$ false; non-romantic friend, $1=$ non-romantic friend, $0=$ false; and romantic partner, $1=$ romantic partner, $0=$ false.

The outputs from conducting logistic regression provide information about the existence of a relationship between the independent and dependent variables (Hosmer \& Lemeshow, 2000). The $\beta$ value provides information about the direction of the relationship; A positive $\beta$ value indicates that as the independent variable increases, the likelihood of "check-in" frequency increases. Inversely, a negative $\beta$ value indicates that as the value of the independent variable decreases, the likelihood of "check-in" frequency decreases. Logistic regression further provides odds ratio information $(O / R)$ that describes the odds of the dependent variable occurring given a range in the independent variables. Odd ratio values greater than 1.0 signify that the variable being evaluated increases the odds of "checking-in" more frequently. Odd ratio values of less than 1.0 signify that the variable being evaluated decreases the odds of "checking-in" more frequently. An odd ratio value of exactly 1.00 indicates an equal likelihood of "checkins," meaning "check-in" frequency cannot be accurately predicted and that there is not a statistically significant relationship (Menard, 2002). Variables that are determined to be statistically significant have been identified as those indicators that are not happening by chance. For the purpose of this research a significance level of $p<.05$ has been established. However, it is possible that an independent variable can have a high odds ratio suggesting an increased likelihood of "checking-in" more frequently, but not demonstrate statistical significance. The odds ratio indicates the probability of "check-in" 
frequency with respect to the given independent variables, but it does not rule out the possibility of it happening by chance.

Before examining the associations between homophily and relational closeness, and "check-in" frequency, a correlation analysis was performed to ensure that the modeled variables were not prohibitively correlated for statistical analyses. When two or more predictor variables are too highly correlated, they may represent the same underlying factor influencing the outcome (Babbie, 2007). More specifically, when there are variables that have correlation coefficients higher than .90 , this can point to multicollinearity. The Pearson correlation coefficient between $0-.29$ is considered to have very low to no association, between $.30-.49$ is considered a weak association, between $.50-.79$ is considered to be moderately associated, between $.80-.99$ is strongly associated, and a value of 1 is a perfect positive association (Babbie, 2007). When looking at the correlation matrix in Appendix B, it can be seen that the highest correlation is $0.445(\mathrm{p}<.01)$, between attitudinal homophily and background homophily. Although there were some statistically significant correlations, none of the independent variables were strongly correlated above the r-square value of .445, and thus all variables were viable to be modeled. Specifically, there was a positive but weak association between attitude homophily $(r=.41, p<.01)$ background homphily $(r=.32, p<.01)$ and geographic proximity $(\mathrm{r}=.34, p<.01)$ with relational closeness, and a negative and weak relationship between sex homophily $(r=-.35, p<.01)$ and relational closeness. Moreover, there was a positive but weak association between background homphily ( $r=$ $.45, p<.01)$ and geographic proximity $(r=.11, p<.05)$ with attitude homophily. In addition, there was a positive but weak association between race homohpily $(r=.21, p<$ 
$.01)$ and length of friendship $(r=.21, p<.01)$ with background homophily. Lastly, there was a negative and weak association between geographic proximity $(r=-.22, p<.01)$ and background homophily.

After checking for multicollinearity, independent samples t-tests were used to illustrate the bivariate relationship between the independent variables and their "friend" by “check-in" frequency. These types of "friends" included romantic partners, nonromantic friends, and family members. The breakdown of the types of "friends" helped detailed the nature of the relationship further. 


\section{Users and their "Friends" on Location-Based Social Network}

The participants in this study included $48 \%$ male and 52\% female. A majority of the participants $(60.5 \%)$ were between the ages of 18 and 29 and, in addition, an even larger majority of the participants were White/Caucasian (71.9\%). See Table 4 below.

Table 4.

Demographics of Users

\begin{tabular}{|c|c|c|}
\hline & $N$ & Percent \\
\hline \multicolumn{3}{|l|}{ Sex } \\
\hline Male & 168 & $47.7 \%$ \\
\hline Female & 183 & $52.0 \%$ \\
\hline \multicolumn{3}{|l|}{ Age } \\
\hline Under 18 & - & - \\
\hline $18-23$ & 99 & $28.1 \%$ \\
\hline $24-29$ & 114 & $32.4 \%$ \\
\hline $30-35$ & 67 & $19.0 \%$ \\
\hline $36-41$ & 32 & $9.0 \%$ \\
\hline $42-47$ & 15 & $4.4 \%$ \\
\hline $48-53$ & 10 & $3.0 \%$ \\
\hline 54 or over & 14 & $4.2 \%$ \\
\hline \multicolumn{3}{|l|}{ Race/Ethnicity } \\
\hline White/Caucasian & 253 & $71.9 \%$ \\
\hline African American & 31 & $8.8 \%$ \\
\hline Hispanic & 19 & $5.4 \%$ \\
\hline Asian & 34 & $9.7 \%$ \\
\hline Native American & 6 & $1.7 \%$ \\
\hline Other & 8 & $2.3 \%$ \\
\hline \multicolumn{3}{|l|}{ Education } \\
\hline$<$ High School & 4 & $1.1 \%$ \\
\hline High School & 51 & $14.5 \%$ \\
\hline Some College & 134 & $38.1 \%$ \\
\hline Bachelors Degree & 123 & $34.9 \%$ \\
\hline Masters Degree & 28 & $8.0 \%$ \\
\hline Doctorate Degree & 4 & $1.1 \%$ \\
\hline Professional Degree & 7 & $2.0 \%$ \\
\hline
\end{tabular}

Note. $N=352$. Only users who are $18+$ were eligible to participate in the study. 
Of the "friends" participants reported to have last "checked-in" with, the majority of the "friends" were White/Caucasian (71.3\%) and, in addition, most of the "friends" were between the ages of 18 and 29 (56.8\%). See Table 5 below.

Table 5.

Demographics of User's "Friend"

\begin{tabular}{lcc}
\hline Sex & $N$ & Percent \\
Male & 180 & $51.1 \%$ \\
Female & 172 & $48.9 \%$ \\
Age & & \\
Under 18 & & \\
$18-23$ & 10 & $2.8 \%$ \\
$24-29$ & 93 & $26.4 \%$ \\
$30-35$ & 107 & $30.4 \%$ \\
$36-41$ & 60 & $17.0 \%$ \\
$42-47$ & 39 & $11.1 \%$ \\
$48-53$ & 19 & $5.4 \%$ \\
54 or over & 8 & $2.3 \%$ \\
& 16 & $4.5 \%$ \\
Race/Ethnicity & & \\
White/Caucasian & & \\
African American & 251 & $71.3 \%$ \\
Hispanic & 35 & $9.9 \%$ \\
Asian & 24 & $6.8 \%$ \\
Native American & 31 & $8.8 \%$ \\
Other & 4 & $1.1 \%$ \\
Not & 7 & $2.0 \%$ \\
\hline
\end{tabular}

Note. $N=352$. Education was not obtained from user's "friend."

Turning to participants' use of LBSNs, Facebook Places was the platform $(74.1 \%)$ that was used most frequently to "check-in" to places. Many of the participants had 150 "friends" (45.7\%) or less on the service they reported using for "checking-in." In terms of "check-in" frequency, $43.5 \%$ of the participants had "checked-in" at least once, or more than once a week with their "friend," while 57\% had "checked-in" less than once a week; Those who "checked-in" at least weekly were considered to "check-in" more frequently, and those who "checked-in" less than weekly were considered to "check-in" less frequently. In addition, of all the venues users could "check-in" with their "friend," 
the workplace was the most popular place for "check-ins," followed by restaurants and coffee shops (See Table 6).

Table 6.

Usage of Location-Based Social Networks (LBSNs)

\begin{tabular}{lcc}
\hline & $N$ & Percent \\
\hline Primary LBSN & 261 & $74.1 \%$ \\
Facebook Places & 43 & $12.2 \%$ \\
Foursquare & 40 & $11.4 \%$ \\
Google Latitude & 8 & $2.3 \%$ \\
Other & & \\
& & \\
Number of "Friends" on LBSN & 81 & $23.0 \%$ \\
Less than 50 & 80 & $22.7 \%$ \\
$50-150$ & 57 & $16.2 \%$ \\
151-250 & 34 & $9.7 \%$ \\
$251-350$ & 100 & $28.4 \%$ \\
More than 350 & & \\
"Check-in" Frequency with "Friend" & & \\
More frequently (at least once or more than once a week) & 153 & $43.5 \%$ \\
Less frequently (less than once a week) & 199 & $56.5 \%$ \\
& & \\
"Check-in" Venues with "Friend" & & - \\
Airport & 58 & - \\
Bar & 139 & - \\
Church & 37 & - \\
Coffee shop & 145 & - \\
Grocery store & 82 & - \\
Gym & 61 & - \\
Restaurant & 245 & - \\
School & 54 & - \\
Shopping & 145 & - \\
Work & 265 & - \\
Other & 51 & - \\
\hline
\end{tabular}

Note. $N=352$

Of the "friendship" connections reported, many participants indicated that they had last "checked-in" with a "friend" whom they considered a romantic partner (46.9\%). In addition, $66.5 \%$ of participants indicated that they had known their "friend" for more than five years, and $54.3 \%$ of participants lived less than 10 miles away from their "friend" (See Table 7). Moreover, results show that $83 \%$ of participants and their "friend" 
were racially homophilous, and $50 \%$ of participants and their "friend" were of the samesex.

Table 7.

User's Relational Characteristics with their "Friend"

\begin{tabular}{lcc}
\hline & $N$ & Percent \\
\hline Type of "Friend" & 121 & $34.4 \%$ \\
$\quad$ Romantic Partner & 165 & $46.9 \%$ \\
$\quad$ Non-Romantic Friend & 66 & $18.8 \%$ \\
Family Member & & \\
Length of Friendship & 234 & $66.5 \%$ \\
$\quad$ Known for more than 5 years & 118 & $33.5 \%$ \\
$\quad$ Known for less than 5 years & & \\
Geographic Proximity & 161 & \\
$\quad$ Lives more than 10 miles away & 191 & $45.7 \%$ \\
$\quad$ Lives less than 10 miles away & & $54.3 \%$ \\
\hline
\end{tabular}
Note. $N=352$

The nature of these relationships was further investigated with questions that explored attitudinal homophily, background homophily, and relational closeness. In each case, a scale from 7: very high similarity (or closeness) to 1: very low similarity (or closeness) was constructed. Participants reported fairly high levels of homophily and relational closeness between themselves and their "friend" (attitude homophily, $M=5.03$, $S D=.97$; background homophily, $M=4.90, S D=1.41$; and relational closeness, $M=$ $5.43, S D=1.41)$. For scales to be reliable, the Cronbach alpha must have an acceptable internal consistency of .70 or higher (Babbie, 2007). Results indicated that the internal consistency of the items measuring the perceived attitudinal homophily ( $\alpha=.92, M=$ 5.03), background homophily $(\alpha=.85, M=4.90)$ and relational closeness $(\alpha=.97, M=$ 5.44) were all highly reliable (See Table $8 \& 9$ for further details). 
Table 8.

User's Attitudinal \& Background Homophily with their "Friend"

\begin{tabular}{lcccc}
\hline & $N$ & $M$ & $S D$ & $\alpha$ \\
\hline Attitude Homophily & 352 & 5.03 & .97 & .92 \\
Background Homophily & 352 & 4.90 & 1.08 & .85 \\
\hline
\end{tabular}

Note. Attitude and background homophily scale: $1=$ Strongly Disagree; $2=$ Disagree; $3=$ Somewhat Disagree; $4=$ Neither; $5=$ Somewhat Agree; $6=$ Agree; $7=$ Strongly Agree

Table 9.

User's Relational Closeness to their "Friend"

\begin{tabular}{lcccc}
\hline & $N$ & $M$ & $S D$ & $\alpha$ \\
\hline Relational Closeness & 352 & 5.43 & 1.41 & .97 \\
\hline
\end{tabular}

Note. Relational closeness scale: $1=$ Strongly Disagree; 2 = Disagree; $3=$ Somewhat Disagree; 4

$=$ Neither; $5=$ Somewhat Agree; $6=$ Agree; $7=$ Strongly Agree

\section{Analysis}

Hypothesis 1 posits that "checking-in" more frequently (vs. infrequently) with a "friend" is positively associated with perceived homophily and relational closeness. To analyze associations between users" "check-in" frequency and their "friend," t-tests were initially used to explore differences in the relational characteristics of frequent and infrequent "check-ins" with "friends." Specifically, independent-samples t-tests were used to compare several descriptive relationship characteristics (e.g., attitude homophily, background homophily, sex homophily, race homophily, relational closeness, geographic proximity, and the length of friendship) by "check-in" frequency (e.g., "less frequently" and "more frequently") within three types of relationships (e.g., non-romantic friend, romantic partner, and family member).

Regarding “checking-in” with a romantic partner, "check-in” frequency was significantly associated with attitude homophily $(p<.05)$, such that users who "checkedin" less frequently $(M=5.37, S D=.81)$ reported slightly higher levels of attitude homophily than those who "checked-in" more frequently $(M=5.02, S D=1.01)$. 
Although users who "checked-in" more frequently with their romantic partner displayed higher levels of relational closeness $(M=6.40, S D=1.12, p=.51)$ and higher levels of background homophily $(M=5.00, S D=.93, p=.66)$ than those that "checked-in" less frequently, it was not significant. In addition, the remaining variables, sex homophily ( $p$ $=.12)$, race homophily $(p=.41)$ geographic proximity $(p=.85)$, and the amount of years $(p=.72)$ users had known their romantic partner, showed no significant differences in “check-in” frequency (See Table 10 for details).

Table 10.

Relational Characteristics of Romantic Partner

\begin{tabular}{clcccc}
\hline Relational Characteristics & "Check-In" Frequency & $N$ & $M$ & $S D$ & $p$ \\
\hline Relational Closeness & Less Frequently & 56 & 6.3899 & 1.12132 & .51 \\
& More Frequently & 65 & 6.5077 & .81206 & \\
Attitude Homophily & Less Frequently & 56 & 5.3702 & .80773 & .04 \\
& More Frequently & 65 & 5.0236 & 1.00336 & \\
Background Homophily & Less Frequently & 56 & 4.9214 & 1.03848 & .66 \\
& More Frequently & 65 & 5.0000 & .92888 & \\
Sex Homophily & Less Frequently & 56 & .0536 & .22721 & .12 \\
& More Frequently & 65 & .1385 & .34807 & \\
Race Homophily & Less Frequently & 56 & .8571 & .35309 & .41 \\
\multirow{4}{*}{ Length of Friendship } & More Frequently & 65 & .8000 & .40311 & \\
& Less Frequently & 56 & 1.7500 & .85812 & .72 \\
Geographic Proximity & More Frequently & 65 & 1.6923 & .90005 & \\
& Less Frequently & 56 & .7857 & .41404 & .85 \\
& More Frequently & 65 & .8000 & .40311 & \\
\hline
\end{tabular}

Note. $N=121$

Regarding "checking-in" with a non-romantic friend, results indicated that while users who "checked-in" more frequently with a non-romantic friend displayed moderately high levels of relational closeness $(M=4.90, S D=1.07)$ than those who “checked-in" less frequently $(M=4.60, S D=1.29)$, it was not significant $(p=.13)$. In addition, there were no significant differences in "check-in" frequency for users' attitudinal homophily $(p=.92)$, background homophily $(p=.98)$, sex homophily ( $p=$ 
$.94)$, race homophily $(p=.39)$ geographic proximity $(p=.83)$, or the amount of years ( $p$ $=.15$ ) users had known their non-romantic friend (See Table 11 for details).

Table 11.

Relational Characteristics of Non-Romantic Friend

\begin{tabular}{llcccc}
\hline & "Check-In" Frequency & $N$ & $M$ & $S D$ & $p$ \\
\hline Relational Closeness & Less Frequently & 101 & 4.6023 & 1.28641 & .13 \\
& More Frequently & 64 & 4.8958 & 1.07121 & \\
Attitude Homophily & Less Frequently & 101 & 4.9749 & .92115 & .92 \\
& More Frequently & 64 & 4.9594 & 1.00078 & \\
Background Homophily & Less Frequently & 101 & 4.7069 & 1.12962 & .98 \\
& More Frequently & 64 & 4.7031 & 1.01042 & \\
Sex Homophily & Less Frequently & 101 & .7129 & .45468 & .94 \\
& More Frequently & 64 & .7188 & .45316 & \\
Race Homophily & Less Frequently & 101 & .7723 & .42145 & .39 \\
\multirow{3}{*}{ Length of Friendship } & More Frequently & 64 & .8281 & .38025 & \\
& Less Frequently & 101 & 1.9406 & .99822 & .15 \\
Geographic Proximity & More Frequently & 64 & 2.1563 & .80116 & \\
& Less Frequently & 101 & .3762 & .48686 & .83 \\
& More Frequently & 64 & .3594 & .48361 & \\
\hline
\end{tabular}

Note. $N=165$

Regarding "checking-in" with a family member, results indicated that "check-in" frequency was significantly $(p=.01)$ associated with race homophily, such that users who "checked-in" with a racially homophilous family member, "checked-in" less frequently $(M=.98, S D=.15)$ than those that "checked-in" more frequently $(M=.83, S D$ $=.38$ ). Although users whom "checked-in" more frequently with a family member displayed higher levels of relational closeness $(M=5.76, S D=1.25)$ than those that “checked-in" less frequently $(M=5.14, S D=1.47)$, it was not significant $(p=.09)$. In addition, the remaining variables, attitude homophily $(p=.49)$, background homophily ( $p$ $=.61)$, sex homophily $(p=.88)$, geographic proximity $(p=.41)$, and length of friendship $(p=.90)$ showed no significant differences in "check-in frequency" (See Table 13 for details). 
Table 12.

Relational Characteristics of Family Members

\begin{tabular}{llcccc}
\hline & "Check-In" Frequency & $N$ & $M$ & $S D$ & $p$ \\
\hline Relational Closeness & Less Frequently & 42 & 5.1369 & 1.47412 & .09 \\
& More Frequently & 24 & 5.7604 & 1.24608 & \\
Attitude Homophily & Less Frequently & 42 & 4.8540 & .94456 & .49 \\
& More Frequently & 24 & 5.0472 & 1.31912 & \\
Background Homophily & Less Frequently & 42 & 5.3071 & 1.14645 & .61 \\
& More Frequently & 24 & 5.1542 & 1.22261 & \\
Sex Homophily & Less Frequently & 42 & .6905 & .46790 & .88 \\
& More Frequently & 24 & .7083 & .46431 & \\
Race Homophily & Less Frequently & 42 & .9762 & .15430 & .01 \\
\multirow{3}{*}{ Length of Friendship } & More Frequently & 24 & .8333 & .38069 & \\
& Less Frequently & 42 & 3.7381 & .91223 & .90 \\
Geographic Proximity & More Frequently & 24 & 3.7083 & .99909 & \\
& Less Frequently & 42 & .4762 & .50549 & .41 \\
& More Frequently & 24 & .5833 & .50361 & \\
\hline
\end{tabular}

Note. $N=66$

To further predict the antecedents of "check-in" frequency, logistic regression was used to analyze the relationship between the independent variables (attitude homophily, background homophily, sex homophily, race homophily, relational closeness, geographic proximity, length of friendship, and "friendship" types including nonromantic friend, romantic partner, and family) and the binary dependent variable ("checking-in" more frequency and "checking-in" less frequently). The overall model is significant at the $p<.01$ level with a $\log$ likelihood of $460.709\left(\chi^{2}=21.238, R^{2}=.079\right)$. Of the ten covariates, only relational closeness and friendship type (i.e., romantic partner) were positively significantly associated with “check-in” frequency on LBSNs. More specifically, results showed that the coefficient for relational closeness was positively statistically significant. The odds ratio for relational closeness indicates that when holding other variables constant, a "friend" who is relationally close is $41 \%$ more 
likely $(\beta=.34, O / R=1.41, p<.01)$ to "check-in" more frequently. This means that for every 1 unit that increased in relational closeness, the possibility of "checking-in" more frequently with a "friend" is increased by $41 \%$.

In addition, results showed that the coefficient for romantic partner was also positively statistically significant. The odds ratio for romantic partner indicates that when holding over variables constant, a "friend" who is a romantic partner is $118 \%$ more likely $(\beta=.78, O / R=2.18, p=.05)$ to "check-in" more frequently. What this means is that for every "friend" that is considered a romantic partner, the possibility of "checking-in" more frequently is increased by $118 \%$.

However, the rest of the independent variables did not reveal any positive, significant relationships with "check-in" frequency, including background homophily ( $p$ $=.81, t$ value $=.12)$, sex homophily $(p=.30, t$ value $=1.06)$, race homophily $(p=.67, t$ value $=.30)$, non-romantic friend $(p=.22, t$ value $=.33)$, geographic proximity $(p=.87, t$ value $=.03)$, and length of friendship $(p=.17, t$ value $=.26)($ See Table 13 for details $)$.

Table 13.

Logistic Regression Model Predicting “Check-In” Frequency on LBSNS

\begin{tabular}{lccccc}
\hline & $\beta$ & S.E. & Wald Statistic & Significance & Odds Ratio \\
\hline Non-Romantic Friend & .406 & .331 & 1.502 & .220 & 1.500 \\
Romantic Partner & .779 & .400 & 3.786 & .052 & 2.179 \\
Geographic Proximity & -.041 & .246 & .028 & .867 & .960 \\
Length of Friendship & .359 & .262 & 1.885 & .170 & 1.432 \\
Relational Closeness & .341 & .120 & 8.129 & .004 & 1.406 \\
Attitude Homophily & -.268 & .140 & 3.669 & .055 & .765 \\
Background Homophily & -.029 & .124 & .056 & .813 & .971 \\
Sex Homophily & .288 & .280 & 1.056 & .304 & 1.333 \\
Race Homophily & -.129 & .302 & .182 & .669 & .879 \\
\hline
\end{tabular}

Notes. $N=352, \chi^{2}=21.238$, Nagelkerke $R^{2}=.079$, Log likelihood $=460.709, p \leq .01$ 


\section{CHAPTER FOUR: DISCUSSION}

\section{Strong Ties on Location-Based Social Networks}

This study hypothesized that users" "check-in" frequency with their "friend" on LBSN will be positively associated with perceived homophily and relational closeness. To test my hypothesis, a survey questionnaire was designed to measure and quantify the factors associated with "check-in" frequency with "friends" on LBSNs. Using binary logistic regression this study identified two factors that were positively and statistically associated with “check-in” frequency. Results showed that users who were relationally close with their "friend" and users whom "checked-in" with their romantic partner were more likely to "check-in" more frequently.

Relational closeness, which evaluated users' perceived level of closeness to their "friend" had a statistically significant relationship to "check-in" frequency. Results indicated that users reported fairly high levels of perceived relational closeness with their "friend" and were $41 \%$ more likely to "check-in" more frequently with those whom they considered close to them. This finding support previous studies (Donath, 2007; Ledbetter et al., 2011) that indicate that frequency of interaction predicts closeness. Specifically, Ledbetter and colleagues (2011) found that frequent activities, such as wall posts, private messages and comments on Facebook were positively associated with perceived relational closeness. This suggests that users in this study whom "checked-in" more frequently with their "friend" did so because there is a strong relationship that exists between them and their "friend." In addition, results of this study also found that users who "checked-in" with a romantic partner were more likely to "check-in" more frequently. Specifically, users were $118 \%$ more likely to "check-in" more frequently with 
a romantic partner. Not surprisingly, this finding supports Granovetter's (1973) and Kelley et al.'s (1983) theory of strong ties, where relationships, such romantic partners, exhibit high levels of closeness, and, in return, reflects high levels of interaction.

It is noteworthy to mention that, while there was not a positive significant association between users' perceived level of homophily with their "friend" and "checkin" frequency, results showed that users and their "friends" are in fact homophilous. For instance, $83 \%$ of LBSN users and their "friend" were racially homophilous. In addition, users also reported being fairly highly homophilous with their "friend" on the attitudinal homophily and background homophily scales. Users reported viewing their "friend" as someone who has thoughts similar to them, shares similar values, and is from a similar background as them. It is not surprising that homophily is not predictive of "check-in" frequency for the reason that, as humans, we are all similar in some ways (McPherson et al., 2001). Because we are all similar in some ways, it becomes less clear as a factor that influences an action or interaction such as "checking-in" more frequently with a "friend" on LBSNs.

\section{Conclusion}

As a result of the strong growth of mobile devices and wireless technologies in the last few years, we have witnessed how media has had an immense influence on how we communicate and how our relationships and interactions with people around us is affected. Before the advent of 'smartphones,' past research on online relationships has predominantly been concerned with how the quality of online relationships compares with offline relationships. One approach has been to examine how social interactions and relationships on SNSs differ from offline social networks. Now as people are ever more 
mobile for work and leisure, they increasingly share information and connect with their friends on various SNSs using their mobile devices, which make it possible to study a user's offline and online activities with their "friends."

As the user base continues to grow on LBSNs, it has become increasingly important to examine the social interactions on LBSNs because LBSNs have not only changed the ways people interact with their "friends," but also have opened up new ways for users to communicate with businesses. These services not only attempt to foster a sense of connectedness between users and their "friends," but have also made it possible for businesses to take advantage of user's digital and physical footprints of the places they visit, by providing exclusive content or in-store offers to those who "check-in." "Check-ins" offer rich data for businesses, including how often users visit specific locations, what users are saying, and with whom users share their locations. Users, as consumers, can now share their opinions on specific physical locations instead of commenting or complaining about services of brands or businesses broadly. An advantage to this is the ability for big brands, such as Starbucks, to respond to issues directly at a regional level.

The findings in this study suggest that app(lication) developers should focus specific efforts on marketing the service as a way for users to interact with close relationships, particular romantic partners, rather than acquaintances or strangers. One possible example could be to modify the service to recognize who users are "checkingin" with and offer specific rewards, such as providing users discounts to shows or movies when users "check-in" with their romantic partners vs. when users "check-in" with acquaintances on their list of "friends." Businesses can also target users based on where 
they visit most frequently. In addition, businesses without a physical location (e.g., clothing lines) can develop partnerships based on strategic locations. For an example, an athletic-apparel company could partner with a retail location and offer users who "checkin" with romantic partners a $20 \%$ discount.

\section{Limitations and Future Research}

It is recommended for future projects of this nature to collect greater variability on each characteristic, as several predicting variables in this study, such as race and age, would have benefited from a larger sample. Conducting research on larger populations could increase the applicability of logistic regression by increasing the sample sizes identified for each variable. A way to increase the depth of data is to consider recruiting participants directly from one or two major LBSNs. One way this might be accomplished is to advertise the study on two of the largest LBSNs: Facebook Places and Foursquare.

Moreover, survey, as a self-reporting measure, also involves systematic bias that can be reduced by adopting various methods of research to yield more significant findings. One way to measure users' perceived homophily and relational closeness more accurately is to collect self-reported data from both users and the "friend" they "checkedin" with.

The findings of this study identified two statistically significant factors that are positively associated with "check-in" frequency on LBSNs. However, due to the use of a quantitative methodology, specifically logistic regression, no conclusions of cause and effect can be drawn from this study. The findings of this study only indicate if a relationship exists between the considered factors and outcomes. Thus, future research should use an experimental methodology to explore follow-up questions such as: "Does 
“checking-in" frequently with a particular relationship (e.g., romantic partner) increase revisits and purchases on LBSNs?" In addition, it would be interesting to explore Haythronthwaite's (2005) concept of media multiplexity with questions such as: "Does the number of media used correlate with "check-in" frequency?" 


\section{END NOTES}

${ }^{\mathrm{i}}$ Historically and more traditionally in academic discourse, the term [friend] refers to nonfamilial platonic ties (Rawlin, 1992). However, SNSs (such as Facebook) use the term [friend] to describe any type of relational connection on their sites, whether they are an offline friend, family member, acquaintance, or even a relative stranger (Rawlin, 1992). Akin to previous studies on SNSs (boyd \& Ellison, 2007; Ellison, Steinfield, \& Lampe, 2011), this study makes a distinction between these two versions of [friend]. On the one hand, "friend" enclosed in double quotation marks will refer to the relational connection that users have on their SNSs. On the other hand, the unmarked term friend (i.e., without single quotation marks) will be used to describe the more

traditional/vernacular friendship relationship.

ii www.foursquare.com

iii www.facebook.com/places

iv When users "check in," they use their mobile device to alert their "friends" where they are and whom they are with through a LBSN (e.g., Facebook Places, Foursquare). This alert typically contains a textual message (e.g., "Lunch with [name]!") and pictures with a hyperlink to the location. Users" "friends" are then able to click on the hyperlink and view specific details of the location including in information about the business/venue, their address, photos of the place, and who has been there.

'Facebook's News Feed is located on the user's home page. It is a convenient method to alert users what their "friends" are up to and interact with them through "liking" and commenting their contents without having to click through individual user's profile page. For more information on how Facebook determines which content to display in a user's News Feed, see https://www.facebook.com/about/newsfeed

vi "Like" or "liking" in double quotation marks refer to the Facebook feature in which users can express their positive sentiment about liking a specific content, including status updates, photos, videos, links, and any info that is shared by "friends" (Hampton et al., 2011).

vii Founded in 2000, Dodgeball was one of the first LBSNs (Humphrey, 2010).

viii Categories are broken down into general groups of places, and then these are broken down once again into further sub-categories. For instance, clicking on the travel category will give users a list of travel locations such as hotels and airports. After the sub-category is chosen (for instance, airport), it will give users the option to get even more specific (for instance, coffee shops inside the airport or gateway) and define the place within the subcategory. If the sub-category is not identified, users can name the location themselves.

${ }^{i x}$ For more information about Facebook Places, see: https://www.facebook.com/help/461075590584469/

${ }^{x}$ Google Latitude. After Google Inc. acquired Dodgeball and shut it down in 2009, Latitude succeeded (Li \& Chen, 2010). In addition to manual "check-ins," Latitude provides users the option to enable automatic "check-ins" - an option that will atomically "check-in" a user to a place that they have designated and "check-out" when a user leaves the place. Latitude is longer in service as of 2012 (Latitude, n.d.). 
${ }^{x i}$ Path was launched in 2010. It encourages users to share photos, places, and things with a limited number of "friends," (Path, n.d.) Unlike other services, Path limits each user to have 150 "friends" encouraging users to connect with only high quality connections. As of May 2015, Path was acquired by Daum Kakao, a South Korean internet company (Russell, 2015).

xii Launched in 2007, SCVNGR was designed for users to "check-in" and complete challenges at places (Vecchione \& Mellinger, 2011). Similar to Foursquare, users can earn points and unlock badges to earn incentives such as discounts or free items. Different from Foursquare however, incentives are offered not by simply "checking-in" at a particular venue but through completing a set of challenges. Challenges are created by participating companies, institutions, organizations, and users of SCVNGR. The number of challenges varies at each location but once the progress bar of a challenge is completed, users can redeem the reward by showing the merchant the reward granted. xiii Purposive sampling is a nonprobability sampling in which the population is selected based on the researcher's own judgement that it's the most useful or representative method (Babbie, 2007). 


\section{REFERENCES}

Abel, H., \& Sahinkaya, R. (1962). Emergence of sex and race friendship preferences. Child Development, 33, 939-943.

Aboud, F. E., \& Mendelson, M. J. (1996). Determinants of friendship selection and quality: Developmental perspectives. p. 87-112 in The Company They Keep: Friendship in Childhood and Adolescence. William M. Bukowski, Andrew Newcomb \& Willard W. Hartup (eds.). New York: Cambridge University Press.

Babbie, E. (2007). The practice of social research (1 $1^{\text {th }}$ ed.). Belmont, CA: Thomson Wadsworth.

Bisgin, H. (2012). A study of homophily on social media. World wide web (Bussum), 1386-145X, 15 (2), 213. DOI: 10.1007/s11280-011-0143-3

boyd, d., \& Ellison, N. (2007). Social network sites: Definition, history, and scholarship. Journal of Computer-Mediated Communication, 13(1). DOI: 10.1111/j.10836101.2007.00393.x

Brandtzaeg, P.B. (2012). Social networking sites: Their users and social implications - a longitudinal study. Journal of Computer-Mediated Communication, 17, 467-488.

Brimicombe, A., \& Li, C. (2009). Location-based services and geo-information engineering. Chichester: Wiley-Blackwell.

Brown, J.J., \& Reingen, P.H. (1987). Socialties and word-of-mouth referral behavior. Journal of Consumer Research, Vol. 14, December, p. 350-62.

Bryant, E. M., \& Marmo, J. (2009). Relational maintenance strategies on Facebook. Paper presented at the annual meeting of the National Communication Association conference, Chicago, IL. 
Bryne, E. (1971). The attraction paradigm. New York: Academic Press.

Buhrmester, D., Kwang, T., \& Gosling, D. (2011). Amazon's Mechanical Turk: A new source of inexpensive, yet high-quality, data? Perspectives on Psychological Science, 3 (6), 13-5.

Cheng, Z., Caverlee, J., Lee, K., Sui, D. Z. (2011). Exploring millions of footprints in location sharing services. In Proceedings of the 4th International Conference on Weblogs and Social Media, ICWSM '11. Menlo Park, CA, USA: AAAI.

Cho, E., Myers, S., \& Leskovec, J. (2011). Friendship and mobility: user movement in location-based social networks. In Proceedings of the $17^{\text {th }}$ ACM SIGKDD International Conference on Knowledge Discovery and Data Mining (KDD). New York, NY, USA: ACM.

Dainton, M., Zelley, E., \& Langan, E. (2003). Maintaining friendships throughout the lifespan. In D.J. Canary \& M. Dainton (Eds.), Maintaining relationships through communication (pp. 79-102). Mahwah, NJ: Lawrence Erlbaum Associates.

Derlega, V. J., \& Chaikin, A. L. (1977). Privacy and self-disclosure in social relationships. Journal of Social Issues, 33, 102-115.

Dibble, J. L., Levine, T. R., \& Park, H. S. (2012). The unidimensional relationship closeness scale (URCS): Reliability and validity evidence for a new measure of relationship closeness. Psychological Assessment, 24, 565-572.

Donath, J. (2007). Signals in social supernets. Journal of Computer-Mediated Communication, 13(1), Retrieved July 2, 2012 from: http://jcmc.indiana.edu/vol2013/issue2001/donath.html. 
Doyle J. M., \& Kao, G. (2007). Friendship choices of multiracial adolescents: Racial homophily, blending, or amalgamation? Social Science Research, 36:633-653.

Ellison, N., Vitak, J., Lampe, C., Gray, R., \& Brooks, B. (2011). Cultivating social resources: The relationship between bridging social capital and Facebook use among adults. Paper presented at the iCS-OII 2011 "A Decade in Internet Time" Symposium. Oxford, UK.

Facebook Places [Website]. (n.d.). Retrieved December 15 2012, from: https://www.facebook.com/places

Facebook statistics [Website]. (n.d.). Facebook newsroom company info. Retrieved December 15 2012, from: https://newsroom.fb.com/company-info/

Festinger, L., Schachter, S., \& Back, K. (1950). Social pressures in informal groups: A study of human factors in housing. Stanford, CA: Stanford University Press.

Foursquare [Website]. (n.d.). Retrieved March 2 2012, from: www.foursquare.com/

Foursquare by the numbers [Website]. (n.d.). Foursquare about us. Retrieved June 12 2015 from: https://foursquare.com/about

Foursquare infographic [Website]. (n.d.). Foursquare blog. Retrieved January 242011 , from: http://blog.foursquare.com/2011/01/24/2010infographic/

Granovetter, M.S. (1973). The strength of weak ties. The American Journal of Sociology, $78(6), 1360-1380$.

Gilbert, E., \& Karahalios, K. (2009). Predicting tie strength with social media. Proceedings of the ACM Conference on Human Factors in Computing Systems (p. 211-220). New York,NY: ACM Press. 
Grove, J. (2010a). Foursquare nearing 1 million check-ins per day. Retrieved July 2, 2012 from: http://mashable.com/2010/05/28/foursquare-checkins/

Grove, J. (2010b). Mayors of starbucks now get discounts nationwide with foursquare. Mashable. Retrieved July 2, 2012 from: http://mashable.com/2010/05/17/starbucks-foursquare-mayor-specials/

Hallinan, M., \& Kubitschek, W. N. (1988). The effects of individual and structural characteristics on intransitivity in social networks. Social Psychology Quarterly, 51: 81-92.

Hampton, K., \& Wellman, B. (2001). Long distance community in the network society: Contact and support beyond netville. American Behavioral Scientist, 45, 476-495.

Hampton, K., Goulet, Rainie, L., K. Purcell, K. (2011). Social networking sites and our lives. Pew Internet and American Life Project. Washington, DC.

Hays, R. B. (1985). A longitudinal study of friendship development. Journal of Personality and Social Psychology, 48, 909-924.

Hargreaves, D. (2011). The reality behind the "check-in" hype. Retrieved July 2, 2012 from: http://www.bynd.com/blog/social-loco-research/

Haythornthwaite, C. (2005). Social networks and internet connectivity effects. Information, Communication, \& Society, vol. 8, no. 2, pp. 125-147.

Hosmer, D. W., \& Lemeshow, S. (2000). Applied logistic regression (second ed.). New York: Wiley.

Humphreys, L. (2010). Media social networks and urban public space. New Media \& Society, 1-16. DOI: $10.1177 / 1461444809349578$ 
Kalmijn M. (1998). Intermarriage and homogamy: causes, patterns and trends. Annual Review of Sociology. 24:395-421.

Kalmijn, M. (2002). Sex segregation of friendship networks: Individual and structural determinants of having cross-sex friends', European Sociological Review, vol. 18, no. $1,101-17$.

Latitude [Website]. (n.d.). Latitude has been tired. Retrieved June 12 2015, from: https://support.google.com/gmm/answer/3001634?hl=en

Lauw, H., Shafer, J.C., Agrawal, R., \& Ntoulas, A. (2010). Homophily in the digital world: a Livejournal case study. Internet Computing, 14. DOI: 10.1109/MIC.2010.25

Lazarsfeld, P. F., \& Merton, R. K. (1954). Friendship as a social process: A substantive and methodological analysis. In M. Berger (Ed.), Freedom and Control in Modern Society (18-66). New York: Van Norstrand.

Ledbetter, A. M., Broeckelman-Post, M. A., \& Krawsczyn, A. M. (2011). Modeling everyday talk: Differences across communication media and sex composition of friendship dyads. Journal of Social and Personal Relationships, 28(2), 223-241.

Li, N. \& Chen, G. (2010). Sharing location in online social networks. IEEE network (0890-8044), 24 (5), p. 20. DOI: 10.1109/MNET.2010.5578914

Lindqvist, J., Cranshaw, J., Wiese, J., Hong, J., \& Zimmerman, J. (2011). I'm the mayor of my house: Examining why people use foursquare-a social-driven location sharing application. In Proceedings of the SIGCHI Conference on Human Factors in Computing Systems (CHI '11), ACM (New York, NY, USA, 2011), 24092418. 
Madden, M. \& Zickuhr, K. (2011). Social networking sites report. Retrieved from: http://pewinternet/org/reports/2011/social-networking-sites.aspx

Marsden, P. V., \& Campbell, K. E. (1984). Measuring tie strength. Social Forces, 63, $482-501$.

McCroskey, L., McCroskey, C., \& Richmond. (2006). Analysis and improvement of the measurement of interpersonal attraction and homophily. Communication Quaterly, 54(1), 1-21.

McPherson, M., Smith-Lovin, L. (1987). Homophily in voluntary organizations: Status distance and the composition of face-to-face groups. American Sociological Review, 52(3), 370-379.

McPherson, M., Smith-Lovin, L., \& Cook, M. (2001). Birds of a feather: Homophily in social networks. Annual Review of Sociology, 27, 415-444.

Menard, S. (2002). Applied logistic regression analysis (2nd ed.). Thousand Oaks, CA: Sage.

Monge, P. R., \& Contractor, N. S. (2003). Theories of Communication Networks. New York: Oxford University Press.

Mouw, T., \& Entwisle, B. (2006). Residential segregation and interracial friendship in schools. American Journal of Sociology, 112(2):394-441.

Newcomb, T. M. (1961). The acquaintance process. New York: Holt, Rinehart \& Winston.

Li, N. \& Chen, G. (2010). Sharing location in online networks. IEEE: The Magazine of Global Internetworking, Volume 24 Issue 5, September/October 2010. 
Oswald, D. L., \& Clark, E. M. (2003). Best friends forever?: High school best friendships and the transition to college. Personal Relationships, 10: 187-196.

Papacharissi, Z. (2002a). The self online: The utility of personal homepages. Journal of Broadcasting and Electronic Media, 46(3), 346-368.

Papacharissi, Z . (2002b). The presentation of the self in virtual life: Characteristics of personal home pages. Journalism and Mass Communication Quarterly, 79, 643660.

Path [Website]. (n.d.). Retrieved March 2 2012, from: www.path.com/

Priest, R. F., \& Sawyer, J. (1967). Proximity and peership: Basis of balance in interpersonal attraction. American Journal of Sociology, 72, 633-649.

Rawlins, W. K. (1992). Friendship matters: Communication, dialectics and the life course. Hawthorne, NY: Aldine de Gruyter.

Rogers, E. M., \& Shoemaker, F. F. (1971). Communication of Innovations: A CrossCultural Approach. Free Press: New York, NY.

Russell, J. (2015). What is Daum Kakao and why did it buy Path? Retrieved June 12 2015, from: http://techcrunch.com/2015/05/29/what-is-daum-kakao-and-why-didit-buy-path

Shrum, W., Cheek, N., \& Hunter, S. (1988). Friendship in school: Gender and racial homophily. Sociology of Education, 61, 227-239.

Steinfield, C., Ellison, N., \& Lampe, C. (2008). Social capital, self-esteem, and use of online social network sites: A longitudinal analysis. Journal of Applied Developmental Psychology, 29, 434-445. 
Subrahmanyam, K., Reich, S. M., Waechter, N., \& Espinoza, G. (2008). Online and offline social networks: Use of social networking sites by emerging adults. Journal of Applied Developmental Psychology, 29: 420-433.

Turner, J. C. (1987). Rediscovering the social group: A self-categorizing theory. Oxford: Blackwell.

Vecchione, A. E., \& Mellinger, M. (2011). Beyond Foursquare: Library treks with SCVNGR. Handheld Librarian IV. Available at: http://works.bepress.com/amy vecchione/23

Verbrugge, L. M. (1983). A research note on adult friendship contact: a dyadic perspective. Social Forces, 62:78-83.

Verbrugge, L. M. (1977). The structure of adult friendship choices. Social Forces, $56: 576-97$.

Wasserman, S. \& Faust, K. (1995). Social Network Analysis. Cambridge: Cambridge University Press, 140-141; 449.

Wellman, B., Salaff, J., Dimitrova, D., Garton, L., Guila, M., \& Haythornthwaite, C. (1996). Computer networks as social networks: Collaborative work, telework, and virtual community. Annual Sociological Review, 22, 213-238.

Wright, K. B. (2000). Perceptions of on-line support providers: An examination of perceived homophily, source credibility, communication and social support within on-line support groups. Communication Quarterly, 48, 44-59.

Zickuhr, K., \& Smith, A. (2010). 4\% of online Americans use location-based services. Pew Internet \& American Life Project. 


\section{APPENDIX A: CONSENT FORM AND DATA COLLECTION SURVEY}

\section{Dear Participant:}

You are invited to participate in a research study conducted by Jacqueline Vo from Portland State University, Department of Communication. This study is conducted in partial fulfillment for a master's degree. The purpose of this study is to examine the varying uses of online and mobile activities. If you decide to participate, you will be asked to complete a set of questions regarding your online and mobile activities. While participating in this study, it is possible that you might feel uncomfortable answering some questions regarding your online and mobile activities. However, your participation is confidential and anonymous. Any information that is obtained in connection with this study and that can be linked to you or identify you will be kept confidential. All information of this research will not include any individual information by which you could be identified. Taking part in this study is completely voluntary. If you choose to participate in this study, you can withdraw at any time, should you wish to stop.

Disclaimer: Only qualified participants will receive a payment of 25 cents for completing the survey. The survey takes approximately 10-15 minutes to complete. If you are not qualified, you will not receive any payment.

If you have questions or concerns about your participation in this study, contact Jacqueline Vo at vojacque@gmail.com. If you have concerns about your rights as a research subject, please contact Research and Strategic Partnerships, Market Center Building 6th floor, Portland State University, (503) $725 \square 4288$.

By proceeding to participate in this study, you have read and understand the information provided above and consent to participate in this research, and you are certifying that you are 18 years of age or older.

- Proceed

- Decline

\section{Qualified Screening}

1. A location-based service is a website or mobile application (like Foursquare or Facebook) that allows you to check-in to places and log where you've been. Do you use any online service to check-in to places?

- Yes

- No

\section{LBS Data}

Instructions: Please answer the following questions with the location-based service that you use MOST FREQUENTLY. You may use your smartphone or web browser to refresh your memory and help you answer these questions. 
2. Please indicate the location-based service you use MOST FREQUENTLY to check-in to places.

- Facebook

- Foursquare

- Google

- Path

- SCVNGR

- Other

3. Approximately how many friends do you have on "(location-based service)"? [Text box]

\section{Homophily}

Instructions: In this section, please think of the LAST person you checked-in to a place with. It is very important that this is the LAST person you checked-in with. Please feel free to check your "(location-based service)" account to verify who this was. In the box below, please provide either the first name only or initials of the person you LAST checked-in to a place with.

The following questions are about "(name of friend)." Please rate how much you agree or disagree about each statement.

4. This person thinks like me.

5. This person doesn't behave like me.

6. This person is different from me.

7. This person shares my values.

8. This person is like me.

9. This person treats people like I do.

10. This person doesn't think like me.

11. This person is similar to me.

Again, the following questions are about "(name of friend)." Please rate how much you agree or disagree about each statement.

12. This person doesn't share my values.

13. This person behaves like me.

14. This person is unlike me.

15. This person doesn't treat people like I do.

16. In this row, select Strongly Agree.

17. This person has thoughts and ideas that are similar to mine.

18. This person expresses attitudes different from mine.

19. This person has a lot in common with me.

20. This person is from a social class similar to mine.

The following questions again are about "(name of friend)." Please rate how much you agree or disagree about each statement.

21. This person's status is different from mine. 
22. This person is from an economic situation different from mine.

23. This person's background is similar to mine.

24. This person's status is like mine.

25 . This person is from a social class different from mine.

26. This person is from an economic situation like mine.

27. This person's background is different from mine.

28. This person and I come from a similar geographic region.

29. This person's life as a child was similar to mine.

\section{Person Data}

30. What type of person is "(name of friend)" in relationship to you?

- Family member

- Friend, non-romantic

- Friend, romantic

- Spouse or legal partner

31. What type of family member is "(name of friend)"?

- Mother

- Father

- Son

- Daughter

- Sister

- Brother

- Cousin

- Niece

- Nephew

- Uncle

- Aunt

- Grandpa

- Grandma

- Other

32. Please give the best guess of how old "(name of friend)" is.

- Under 18

- $18-23$

- 24-29

- $30-35$

- $36-41$

- $42-47$

- $48-53$

- 54 or over

33. What is the sex of "(name of friend)"?

- Male 
- Female

34. Please give the best guess of "(name of friend)'s" ethnicity.

- White/Caucasian

- African American

- Hispanic

- Asian

- Native American

- Pacific Islander

- Other

35. How many years have you known "(name of friend)"?

- Less than 5 years

- 5-10 years

- 11-20 years

- 21-30 years

- 31-40 years

- 41-50 years

- More than 50 years

36. What types of topics do you discuss with "(name of friend)"? (CHECK ALL THAT APPLY.)

- Family

- Friends

- Leisure

- Local Events

- Politics

- Work

- Other

37. How often do you check-in to places with "(name of friend)" on "(location-based service)"?

- Daily

- 2-3 Times a Week

- Once a Week

- 2-3 Times a Month

- Once a Month

- Less than Once a Month

38. What types of venues or places do you check-in with "(name of friend)" on "(location-based service)"? (CHECK ALL THAT APPLY.)

- Airport

- Bar 
- Church

- Coffee shop

- Grocery Store

- Gym

- Restaurant

- School

- Shopping

- Work

- Other

39. Approximately, how many miles away does "(name of friend)" live from you?

- Less than 10 miles

- 10-20 miles

- 21-30 miles

- 31-40 miles

- 41-50 miles

- More than 50 miles

\section{Relational Closeness}

The following questions refer to your relationship with "(name of friend)." Please rate how much you agree or disagree about each statement.

40. My relationship with "(name of friend)" is close.

41. When we are apart, I miss "(name of friend)" a great deal.

42. "(Name of friend)" and I disclose important personal things to each other.

43. "(Name of friend)" and I have a strong connection.

44. "(Name of friend)" and I want to spend time together.

45. I'm sure of my relationship with "(name of friend)."

Again, the following questions refer to your relationship with "(name of friend)." Please rate how much you agree or disagree about each statement.

46. "(Name of friend)" is a priority in my life.

47. "(Name of friend)" and I do a lot of things together.

48. When I have free time I choose to spend it alone with "(name of friend)."

49. I think about "(name of friend)" a lot.

50. In this row, select Somewhat Agree.

51. My relationship with "(name of friend)" is important in my life.

52. I consider "(name of friend)" when making important decisions.

\section{Demographics}

Instructions: Please answer or select the response which best describes YOURSELF.

53. What year were you born? [Drop down menu by year]

54. What is your sex? 
- Male

- Female

55. What is your ethnicity?

- White/Caucasian

- African American

- Hispanic

- Asian

- Native American

- Pacific Islander

- Other

56. What is the highest level of education that you have completed?

- Less than High School

- High School Degree (or GED)

- Some College (e.g., 1 year, 2, years, 3 years)

- Bachelors Degree (e.g., BA, BS)

- Masters Degree (e.g., MA, MS)

- Professional Degree beyond Bachelors Degree (e.g., MD, DDS)

- Doctorate Degree (e.g., Ph.D.) 
APPENDIX B: MULTICOLLINEARITY CHECK

\begin{tabular}{|c|c|c|c|c|c|c|c|}
\hline $\begin{array}{l}\text { Multicollinearity } \\
\text { Check }\end{array}$ & $\begin{array}{l}\text { Relational } \\
\text { Closeness }\end{array}$ & $\begin{array}{c}\text { Attitude } \\
\text { Homophily }\end{array}$ & $\begin{array}{l}\text { Background } \\
\text { Homophily }\end{array}$ & $\begin{array}{c}\text { Sex } \\
\text { Homophily } \\
\end{array}$ & $\begin{array}{c}\text { Race } \\
\text { Homophily }\end{array}$ & $\begin{array}{l}\text { Geographic } \\
\text { Proximity }\end{array}$ & $\begin{array}{l}\text { Length of } \\
\text { Friendship }\end{array}$ \\
\hline $\begin{array}{l}\text { Relational } \\
\text { Closeness }\end{array}$ & & & & & & & \\
\hline $\begin{array}{l}\text { Attitude } \\
\text { Homphily }\end{array}$ & $.413^{* *}$ & & & & & & \\
\hline $\begin{array}{l}\text { Background } \\
\text { Homophily }\end{array}$ & $.323^{* *}$ & $.445^{* *}$ & & & & & \\
\hline $\begin{array}{l}\text { Sex } \\
\text { Homophily }\end{array}$ & $\begin{array}{c}.000 \\
-.349^{* *}\end{array}$ & $\begin{array}{l}.000 \\
-.061\end{array}$ & -.038 & & & & \\
\hline $\begin{array}{l}\text { Race } \\
\text { Homophily }\end{array}$ & $\begin{array}{l}.000 \\
.013\end{array}$ & $\begin{array}{l}.256 \\
.047\end{array}$ & $\begin{array}{l}.472 \\
.213^{* *}\end{array}$ & . 045. & & & \\
\hline $\begin{array}{l}\text { Geographic } \\
\text { Proximity }\end{array}$ & $\begin{array}{l}.815 \\
.344^{* *}\end{array}$ & $\begin{array}{l}.378 \\
.106^{*}\end{array}$ & $\begin{array}{l}.000 \\
.082\end{array}$ & $\begin{array}{c}.397 \\
-.222^{* *}\end{array}$ & -.052 & & \\
\hline $\begin{array}{l}\text { Length of } \\
\text { Friendship }\end{array}$ & $\begin{array}{l}.000 \\
-.053\end{array}$ & $\begin{array}{c}.047 \\
-.017\end{array}$ & .126 & $\begin{array}{l}.000 \\
.217^{* *}\end{array}$ & $\begin{array}{l}.329 \\
.062\end{array}$ & -.060 & \\
\hline Notes $N=352$ & $* .325$ & .752 & . 000 & . 000 & . 244 & .261 & \\
\hline
\end{tabular}

